\title{
Spatial variability in the relation between fire weather and burned area: patterns and drivers in Portugal
}

\author{
Tomás Calheiros $^{1}$, Akli Benali ${ }^{2}$, João Neves Silva ${ }^{2}$, Mário Pereira ${ }^{3,4}$, and João Pedro Nunes ${ }^{1,5}$ \\ ${ }^{1}$ cE3c: centre for Ecology, Evolution and Environmental changes, Faculdade de Ciências, Universidade de Lisboa, Lisboa, \\ Portugal \\ ${ }^{2}$ Centro de Estudos Florestais, Instituto Superior de Agronomia, Universidade de Lisboa, Tapada da Ajuda, 1349-017 Lisboa, \\ Portugal \\ ${ }^{3}$ Centro de Investigação e de Tecnologias Agro-Ambientais e Biológicas (CITAB), Universidade de Trás-os-Montes e Alto \\ Douro, Vila Real, Portugall \\ ${ }^{4}$ IDL, Universidade de Lisboa, Lisboa, Portugall \\ ${ }^{5}$ Soil Physics and Land Management group, Wageningen University and Research, Wageningen, Netherlands
}

Correspondence: Tomás Calheiros (tlmenezes@fc.ul.pt)

\begin{abstract}
Fire weather indices are used to assess the effect of weather conditions on wildfire behaviour and the high Daily Severity Rating percentile (DSRp) is strongly related to the total burned area (BA) in Portugal. The aims of this study were to: 1) assess if the 90th DSRp (DSR90p) threshold is adequate for Portugal;2) identify and characterize regional variations of the DSRp threshold that justifies the bulk of BA; and, 3) analyse if vegetation cover can explain the DSRp spatial variability. We used wildfire data, weather reanalysis data from ERA5, for the 2001 - 2019 period, and the land use map for Portugal. DSRp were computed for an extended summer period and combined with individual large wildfires. Cluster analysis was performed using the relationship between DSRp and BA, in each municipality. Results revealed that the DSR90p is an adequate threshold for Portugal and well related to large BA. However, at the municipality scale, differences appear between the DSRp linked to the majority of accumulated BA. Cluster analysis revealed that municipalities where large wildfires occur in high DSRp present higher BA in forests and are located in coastal areas. In contrast, clusters with lower DSRp present greater BA in shrublands and are situated in eastern regions. These findings can support better prevention and fire suppression planning.
\end{abstract}

\section{Introduction}

Wildfire incidence depends on weather, especially in regions with a Mediterranean-type climate, where rainy winters and springs favour vegetation growth, while dry and hot summers promote thermal and hydric stress of live fuels and dryness of dead fuels (Romano and Ursino, 2020). The Iberian Peninsula is the European region with the highest wildfire incidence and consequently, suffers large property damage and fatalities (San-Miguel-Ayanz et al., 2020). The impacts of droughts on vegetation can create favourable conditions for the ignition and spread of wildfires, especially in summer (Pausas and 
Fernández-Muñoz, 2012; Russo et al., 2017), but also in winter (Amraoui et al., 2015; Calheiros et al., 2020). Heatwaves and droughts have a strong influence on fire incidence, as shown by several studies in the last years in Mediterranean Europe (Duane and Brotons, 2018; Sutanto et al., 2020). Fire incidence can increase dramatically with the combined effect of prolonged drought and heatwaves, as pointed by Ruffault et al., (2018) in Mediterranean France, or as occurred in the catastrophic fires of 2017 in Portugal (Turco et al., 2019). Other studies identified weather-types associated with large fires, most of them connected with heatwaves or droughts in the western Iberian Peninsula (Rodrigues et al., 2020; Vieira et al., 2020). The influence of climate variability on fire incidence became more evident after the 1970s, following a fire regime change, from fuel-limited to drought-driven in Western Mediterranean (Pausas and Fernández-Muñoz, 2012). The main factor for this change was the increase of fuel load and continuity due to the rural depopulation and land abandonment (Moreira et al., 2011; Moreno et al., 2014), creating conditions for the occurrence of large fires (Ferreira-Leite et al., 2016). Large fires mostly occurred with severe fire weather conditions, being rare in other meteorological conditions (Telesca and Pereira, 2010); and the contribution of landscape-level fuel connectivity to fire size was evident, analysing the 1998 - 2008 period (Fernandes et al., 2016). These changes in landscape, together with socioeconomic changes, impact the fire regime (Pereira et al., 2014; Parente and Pereira, 2016; Parente et al., 2018). Future climate change will increase fire incidence in the Mediterranean Europe (Sousa et al., 2015; Turco et al., 2018). Fire regime can be defined as a combination of these variables, namely climate, vegetation type and continuity, variability of burnt area and number of fires, or others. Cluster analysis for the Iberian Peninsula has identified several regions with similar fire regime, using several variables related to fire, as intra-annual pattern of burnt area (Trigo et al., 2016; Calheiros et al., 2020; Calheiros et al., 2021), fire activity and weather risk (Jimenez-Ruano et al., 2018), large fire-weather typologies (Rodrigues et al., 2020) or burnt area tendency (Silva et al., 2019). Fire weather danger indices are commonly used to assess the current and/or cumulative effect of atmospheric conditions on fuel moisture and fire behaviour. The Canadian Forest Fire Weather Index (FWI) System (CFFWIS) consists of six components that account for those effects (Van Wagner, 1987), including the Daily Severity Rating (DSR). The 90th percentile of the DSR (DSR90p) is often used as the threshold for severe fire weather that is associated with large fires (Carvalho et al., 2008; Bedia, Herrera and Guti, 2012; Fernandes, 2019; Silva et al., 2019). More recently, the 95th percentile of DSR was also identified as a good indicator of extreme fire weather and well related to the burnt area in the Iberian Peninsula (Calheiros et al., 2020; Calheiros et al., 2021). Burnt area and extreme fire weather days have a strong link, noticeable in the similar intra-annual variability pattern in the four pyro-regions of the Iberian Peninsula (Calheiros et al., 2020). This robust link was used to anticipate fire regime changes caused by future climate change, revealing the potential displacement of fire regimes to the north (Calheiros et al., 2021). Portugal has been severely affected by wildfires in last decades, especially in 2003, 2005 and 2017 (Trigo et al., 2006; Gouveia et al., 2012; Turco et al., 2019). Wildfires in Portugal were the subject of several studies that developed zoning approaches with the purpose of identifying regions with similar fire regime using burnt area data (Scotto et al., 2014; Kanevski and Pereira, 2017), combined with fire weather indices (Calheiros et al., 2020; Calheiros et al., 2021), population density, topography, land cover changes (Oliveira et al., 2017) and net primary production (Fernandes, 2019), or fire prevention policy decisions (Parente et al., 2016). Generally, clustering results indicate that Portugal can be divided into two (dividing the north and south of Tajo River) or three main clusters (the north part further divided in western and eastern). Oliveira et al. (2017) added a fourth cluster in the central 
littoral region. Actually, the spatial and temporal distribution of wildfires presents clustering patterns, suggesting that small fires are more dependent on local topographic or human conditions, while large fires are a consequence of infrequent causes or with shorter periods such as weather extreme events (Pereira et al., 2015). The temporal pattern is characterized by periodicities and scaling regimes (Telesca and Pereira, 2010) including a main summer fire season and a secondary spring peak, both driven by the type of climate and the occurrence of extreme weather conditions (Amraoui et al., 2015; Trigo et al., 2016; Calheiros et al., 2020). There have been important changes in land use since the 1960s in Portugal which are related with wildfire occurrence. Arable cropland decreased from $40 \%$ to only $12 \%$ of the total area in 2006, at national level; and forest declined since the 1980s, as a result of forest fires, in the Centro research area (Jones et al., 2011). Shrublands are more susceptible to wildfires, whereas agricultural areas and agroforestry systems are less likely to burn, as revealed by several studies (Carmo et al., 2011; Nunes, 2012; Meneses et al., 2018). Barros and Pereira, (2014) identified shrublands as the most wildfire-prone land cover, followed by pine forests. On the contrary, annual crops and evergreen oak woodlands tend to be avoided by wildfire. Ferreira-Leite et al., (2016) concluded that uncultivated land (shrubs, grass, and other sparse vegetation) was the most important factor affecting burnt areas, considering large wildfires, greater than 100 ha. Topography and uncultivated land were significant factors determining burnt area, in a study for the 1980-2014 period conducted at municipal level (Nunes et al., 2016). The burnt area within the rural-urban interface expanded from 1990 to 2012 (Tonini et al., 2018). There is evidence of an extending urban-rural interface, which contributes to an increase in fire incidence, in north-western Portugal, where agriculture is the dominant land cover type and urban area doubled since 1990 (Silva et al., 2019). Another essential element for fire incidence is the vegetation and land use type. For example, land use interfaces, that are generally between forests and other land use types (shrublands, agricultural and urban), have a significant effect in human-caused wildfire occurrence in Mediterranean Europe, showing that larger interfaces have larger risk of a fire to happen due to human causes (Vilar et al., 2016). Fuel removal can be a solution for the extending area of wildland-urban interfaces (Elia et al., 2016). Wildfires can also modify the landscape in the Mediterranean region (e.g. Stamou et al. (2016)) influenced by regeneration patterns, topography and local fire histories. In the Iberian Peninsula, shrublands and pine forests have registered larger burnt areas (Pausas and Vallejo, 1999; Barros and Pereira, 2014). This fact can be explained by the increasing landscape homogenization, due to shrublands expansion and agricultural abandonment, as observed by Lloret et al. (2002), in eastern Spain. In Portugal, eucalyptus expansion has not modified fire regime, but the rising undermanaged and abandoned forest plantations, especially after large-fire seasons, is a concern for the future (Fernandes, Guiomar and Rossa, 2019). Given the role of extreme weather on large wildfires and the common use of DSR thresholds the objectives of this work were: 1) assess if the DSR90p threshold is adequate for mainland Portugal; 2) identify and characterize regional variations of the DSRp threshold that justifies the bulk of BA, and; 3) analyse if vegetation cover can explain the spatial variability of the DSRp. 


\section{Data and methodology}

\subsection{Study Area: Portugal}

This study focuses in mainland Portugal, a country divided by 23 NUTSIII provinces themselves subdivided into 278 municipalities, and characterized by mountainous areas in north and central regions and vast plains in the south (Figure 1). The burnt area (BA) variability is mainly influenced by the precipitation anomaly in spring and the occurrence of abnormal atmospheric patterns that generate very hot and dry days in the western Iberian Peninsula during summer (Pereira et al., 2005). In fact, 97\% of the total number of extreme fires (fires with burnt area $\geq 5000$ ha) are active during heatwaves (Parente et al., 2018). Almost 90\% of extreme fires during the 1981-2017 period occurred within a region affected by drought (Parente et al., 2019). Fire weather in Portugal has usually been characterized using the CFFWIS (Calheiros et al., 2021; Calheiros et al., 2020; Silva et al., 2019; Nunes et al., 2019; Pereira et al., 2013; Carvalho et al., 2008), which provides good results in comparison with other methods of fire danger evaluation (Viegas et al., 1999).

\subsection{Fire Weather Index and Meteorological Data}

We used the DSR that is based on the Fire Weather Index (FWI) which, in turn, rates the fire intensity and is frequently used to inform the general public about fire weather danger conditions, but more accurately reflects the expected efforts required for fire suppression (De Groot, 1987; Van Wagner, 1987). These indices were computed with the equations provided by Van Wagner and Pickett (1975) and daily values at 12h00UTC of air temperature and relative humidity (at 2 meters), wind speed (at 10 meters), and accumulated total precipitation. The meteorological variables were obtained from the fifth generation of ECMWF atmospheric reanalyses of the global climate (ERA5-Land). The ERA5-Land dataset (Copernicus Climate Change Service (C3S), 2017) has much higher spatial resolution $\left(0.1^{\circ}\right.$ lat $x 0.1^{\circ}$ long; native resolution is $\left.9 \mathrm{~km}\right)$ and temporal (hourly) resolution, compared with previous reanalysis data service, that were widely used and with good performances for FWI in Portugal (Bedia, Herrera and Guti, 2012). We also used the land use and land cover (LULC) map for 2018 (COS2018) provided by DGT (2019), and the wildfire database from the Portuguese Institute for the Conservation of Nature and Forests, for the 2001 to 2019 period (ICNF, 2020). Only large wildfires (BA $>100$ ha) occurring during the extended summer season (considered between 15th May and 31st October) were investigated. When the wildfire affected more than one municipality, BA was allocated to each of the administrative units burned by the wildfire. The starting and ending dates of each wildfire were fundamental information to attribute the DSR to each BA. This process was accomplished using MODIS satellite data, computed using the same method as in Benali et al. (2016), with start and end dates and ignition location estimated for circa $92 \%$ of the total BA, for large wildfires. Daily DSR was computed for the same period (2001 - 2019) and for all ERA5-Land grid points within continental Portugal. The size of Portuguese municipalities is relatively small, so there are no major weather variations within. Therefore, only the DSR maximum in each municipality was retained to characterize daily fire weather conditions. Afterwards, in each administrative unit, we computed the DSR percentiles (DSRp) and assigned to the BA within the unit. Moreover, we selected the maximum DSR over the duration of the fire, in those extending more than one day. BA data were normalized using both the decimal logarithm and fraction of the total burnt area (FTBA), in percentage. Exploratory analysis showed that the BA 
extent of individual small fires was poorly correlated with DSRp and, consequently, sorting was performed. Afterwards, BA for the entire mainland Portugal territory were sorted by assigned DSRp and the Log (Total Burnt Area) $(\log ($ TBA)) was plotted against DSRp to assess if this relationship is linear. Subsequently, we analysed if a fixed threshold for extreme days, DSR90p, is adequate for the entire territory to estimate extreme fire weather and well related to large BA. We considered the correspondent $80 \%$ and $90 \%$ of FTBA as sufficient to classify DSRp as the extreme threshold, justified by the results of Pereira et al., (2005), which showed that $80 \%$ of BA occurs in $10 \%$ of summer days. We selected 175 municipalities (from 278) affected by more than three individual wildfires and a total $B A>500$ ha in the studied period $(2001-2019)$. Restricting the analysis to the administrative units with sufficient data aims to increase the robustness of the results and to prevent possible interpretation errors. Figures assessing the relation between DSRp and FTBA were produced, for all the selected municipalities, with the purpose to answer the second research question. In each municipality, the selection of the maximum spatial value of DSR to associate with fires is justified by the low spatial variability of the DSR, small size of administrative units and the native reanalysis data resolution (Copernicus Climate Change Service (C3S), 2017). The burnt area division between municipalities can produce noise in the data. This procedure artificially generates wildfires, some of them with relatively small size but high or very high DSRp. To circumvent this difficulty, we decided to analyze BA percentages, which reduce the influence of small wildfires on the final results.

\subsection{Cluster Analysis}

Potential clustering was assessed using the curves of FTBA vs. DSRp for all the selected municipalities. Clusters were computed using "complete" (the longest distance) method, and (1-r2), as the metric, where $\mathrm{r} 2$ is the coefficient of determination between FTBA and DSRp. Method and metric choices are justified to ensure robustness and ease of visualization, respectively. The selected (1-r2) threshold was 0.35 , meaning that coefficient of determination in the municipalities within the cluster is higher than 0.65. Algorithms were processed with Matlab software.

\subsection{The influence of the type of vegetation}

The burnable area (BNA) was computed as the total burnable area (sum of the land cover types that are susceptible to burn based on the land cover map) divided by the total area of the municipality and presented in percentage. The ratio between TBA in the $2001-2019$ period, divided by the total burnable area in the municipality (TBA/BNA), was also computed and presented in percentage. LULC was related with TBA by computing the TBA in the 5 classes of vegetation, namely: forests, shrublands, agriculture, agroforestry and others. Computations were made for each analysed municipality and cluster, to answer the third research question. Two additional ratios were computed, the first between forest and shrublands BNA and the second between forest and shrublands TBA, for each municipality. Moreover, the spatial distribution of prevailing land use types that were most affected by wildfires was investigated to identify which municipalities have BA in forests larger than $50 \%$ or BA in shrublands larger than $40 \%$ of TBA. A contingency table, accuracy metrics and statistical measures of association were used to analyze the influence of the type of vegetation cover on the relationship between DSRp and TBA. The contingency table contains the number of municipalities that are characterized by diverse DSRp thresholds at 90\% of TBA (DSRp90TBA) and, therefore, 
different group of clusters. The objective is to relate the municipalities (within the groups of clusters) with TBA in diverse vegetation cover types, taking in consideration that a pre-conceived relation must be made. For example, we can propose that municipalities with high DSRp90TBA will have the largest TBA in forested areas, comparing with other land use types, and accuracy metrics will be computed according to this initial classification. A contingency table needs, at least, two rows and two columns and, therefore, two relations. The list of accuracy metrics includes: (i) the overall accuracy, which represents the samples that were correctly classified and are the diagonal elements in the contingency table, from top-left to bottom-right (Alberg et al., 2004); (ii) the user's accuracy, or reliability, that is indicative of the probability of a sample that was classified in one category belongs to that category; and, (iii) the producer's accuracy, represents the probability of a sample being correctly classified (Congalton, 2001). Statistical measures are: the Chi-squared $(\chi 2)$ test (Greenwood and Nikulin, 1996), which test the independence of two categorical variables; the Phi-test $(\Phi)$ or phi coefficient (David and Cramer, 1947) is related to the chi-squared statistic for a $2 \times 2$ contingency table, and the two variables are associated if $\Phi>0$. Lastly, we computed the Cohen's Kappa coefficient, firstly presented by Cohen, (1960) and recently analysed by McHugh, (2012), that measures the interrater agreement of the two nominal variables. This coefficient ranges from -1 to 1 and is interpreted as $<0$ indicating no agreement to 1 as almost perfect agreement.

\section{Results}

\subsection{Patterns at national level}

Results for the entire mainland Portugal territory (Figure 2) showed a linear relationship between the Log (TBA) and DSRp, with a very high coefficient of determination $(R 2=0.94)$ and $p$-value lower than significance level. The increase of $\log (\mathrm{TBA})$ is essentially linear, but is exponential (with $\mathrm{R} 2=0.92$ ) for DSRp extreme values (DSR>DSR90p), meaning that BA rises suddenly with extreme meteorological conditions. The analysis of the dependence of FTBA with DSRp in the entire mainland Portugal territory (Figure 3) revealed that most of the TBA occurred with very high DSRp values. For example, for days with DSR $>$ DSR50p the FTBA is almost 100\%, meaning that fires in days with lower DSR have a negligible impact on TBA. Fires in days with DSRp between 85 and 95 were responsible for more than $80 \%$ of TBA in the $2001-2019$ period, making this a good DSRp threshold for extreme days. This justifies using the DSR90p at the national scale, which is widely used for threshold of extreme values (Carvalho et al., 2008; Bedia, Herrera and Guti, 2012; Fernandes, 2019; Silva et al., 2019). However, if the analysis is performed at higher spatial resolution, namely at municipality level, some differences become apparent (Figure 4). The spatial distribution of DSRp for FTBA=80\% (DSRp80TBA) or FTBA=90\% (DSRp90TBA) (Figure 4) in each municipality presents important differences between regions, together with more visible contrasts in DSRp90TBA than in DSRp80TBA. The much lower values of DSRp in the north-eastern (Alto Tâmega, Terras de Trás-os-Montes, Douro and northern Beiras e Serra da Estrela) and in the southern interior regions (Alentejo Central and Baixo Alentejo) should be highlighted. DSRp90TBA is very high in most of the coastal and in some of central hinterland municipalities (portions of Área Metropolitana do Porto, Viseu Dão-Lafões, Região de Coimbra, Beira Baixa and Região de Leiria), reaching values similar to the mean country level value (85 - 95). In some NUTSIII provinces of the northern and central hinterland, DSRp90TBA is between 60 and 70 in 
most of the municipalities, particularly in Douro and Terras de Trás-os-Montes. It is important to underline that DSRp80TBA $>$ DSRp90TBA which is a consequence of the adopted methodology to perform this analysis (please see section 2.1). This also helps understand why DSRp=50 is associated to FTBA=100\% (Figure 3). The spatial distribution of DSRp80TBA and DSRp90TBA suggests the existence of municipality clustering.

\subsection{Patterns at the municipality level}

We explored other features of wildfires in mainland Portugal, with the objective of explaining the differences observed in DSRp at municipality level. Burnable area (BNA), the ratio of Forest/Shrublands BNA, and the ratio of Forest/Shrublands TBA in each municipality were assessed and analysed (Figure 5). Additionally, the number of wildfires and the TBA/BNA ratio in each municipality were also evaluated (see Annexes). Burnable area (Figure 5a) is much lower in coastal municipalities (except in Algarve) and in most of the northern and central hinterland, particularly in Terras de Trás-os-Montes, Douro and portions of Beiras e Serra da Estrela. Those relatively low values are explained by the high density of population and urban areas near the coastline and by agriculture patches in the countryside. On the other hand, higher burnable areas are present in the mountain ranges, especially in the northwest (some municipalities located in Alto Minho, Cávado and Alto Tâmega) as well as in some specific forested regions in central hinterland (within Área Metropolitana do Porto, Viseu Dão-Lafões, Região de Coimbra, Região de Leiria, Médio Tejo and Beira Baixa) and one municipality in Algarve. These patterns are justified by low population density, low availability of land suitable for agriculture, and, in some regions, extensive forest plantations. Results (Figure 5b) also show that forest cover is prevalent in most of the analysed municipalities, with special intensity in the west coast. Conversely, shrublands BNA is more dominant in a few municipalities located in the northern hinterland, particularly situated in Alto Minho, Alto Tâmega, Douro and Beiras e Serra da Estrela. Results are considerably different analysing the Forest/Shrublands TBA (Figure 5c), with an extensive amount of municipalities of the north, including coastal and inland, that have larger TBA in shrublands (large number of municipalities are located in Alto Tâmega, Tâmega e Sousa, Douro, Viseu Dão-Lafões and Beiras e Serra da Estrela). Nevertheless, the municipalities with higher Forest/Shrubland BNA correspond with those with larger ratios of Forest/Shrubland TBA. Results of both maps are similar when analysing the southern provinces of the country (Alto Alentejo, Alentejo Central, Alentejo Litoral, Baixo Alentejo and Algarve), where almost of all municipalities are characterized by higher forest BNA and TBA. Other municipalities also highly affected by fires are located in the extreme northwest (Alto Minho), surrounding mountain ranges in northwest (Área Metropolitana do Porto and Tâmega e Sousa), and in the south (Alto Alentejo and Algarve). By contrast, the lower burnt area percentages occur in most of southern provinces (except Algarve) and in the northeast (Terras de Trás-os-Montes). The largest TBA/BNA is observed in mountains ranges and forested regions of central hinterland, particularly in parts of Viseu Dão-Lafões, Beiras e Serra da Estrela, Região de Coimbra, Região de Leiria, Médio-Tejo and one municipality in Algarve. In some of these municipalities, this value is $>100 \%$, meaning that in the 19-years period TBA is larger than BNA and, consequently, there were a large number of recurrent wildfires in those areas. 


\subsection{Cluster analysis pattern}

Based on the relationship between TBA and DSRp the municipalities were grouped in ten clusters. However, the dendrogram (Figure 6) discloses that cluster 10 is isolated, with only one municipality, and, therefore, can be eliminated from further analysis. Cluster numbers are in descending order of the DSRp90TBA, i.e., 90\% of TBA was registered with DSRp larger than this value. Cluster 2 includes the largest number of municipalities (23\% of total) and highest TBA, almost 500,000 ha (26\% of total). Generally, clusters group 13 or more municipalities, with the exception of cluster 3 and 8 , with only 5 and 6 municipalities, respectively. Each cluster represents between $8 \%$ and $16 \%$ of the total TBA for the study period, except for the two smaller clusters, where TBA is only $1 \%$ of total. The spatial pattern of Figure 7 reveals a uniform distribution of the municipalities of equivalent clusters, meaning that municipalities with similar DSRp are often neighbours. In general, patches of municipalities belonging to consecutive clusters are observed. FTBA=100\% occurs for DSR90p in cluster 1, meaning that large fires only occurred with very extreme meteorological conditions. The FTBA vs. DSRp curves for the first three clusters present a very steep slope for the highest DSRp values (Figure 8), revealing that large fires take place at high percentiles of DSR (above 90). Moreover, the FTBA vs. DSRp plots for these clusters present very low dispersion suggesting that the curves for the municipalities of each of these clusters are similar. These municipalities are located in north and central western coastal areas, also with mountain ranges (predominant in Alto Minho, Cávado, Área Metropolitana do Porto, Tâmega e Sousa, Região de Aveiro, Região de Coimbra and Alentejo Litoral), within some central and south hinterland regions (parts of Viseu DãoLafões, Beiras e Serra da Estrela, Médio-Tejo and Alto Alentejo) and in the south coast (almost all of Algarve). Clusters 4, 5 and 6 are prone to burn with less extreme conditions, where the median of DSR90p corresponds to $85-90 \%$ of TBA. The slope of FTBA vs DSRp curves is less steep than the previous clusters, and dispersion is higher in these clusters, with more municipalities where fire can occur with lower values of DSRp. Both suggest that in these clusters fires in tend to occur in a widest range of meteorological conditions. These clusters are spread throughout the country, and can be viewed as a transition between the group of clusters with extreme (1,2 and 3) and less extreme (7, 8 and 9) DSRp80TBA or DSRp90TBA. Clusters 7, 8 and 9 can be considered as the group of lower DSRp clusters, due the relatively lower values of the DSR90p and of the DSRp80TBA or DSRp90TBA, which range from 70 to $80 \%$. Additionally, higher curve dispersion is also apparent, especially in cluster 9, which integrates municipalities where large wildfires can occur with lower values of DSRp (in some cases, below DSR50p). In this group of clusters, the slope of the FTBA vs DSRp curves, at higher values of DSRp is the lowest, especially in clusters 8 and 9. Nevertheless, the median curve of cluster 8 has a different behaviour, comparing to the other clusters: the steeper interval is between 70th and 80th percentile, meaning that it has a larger amount of BA in less extreme conditions. The municipalities within these clusters are mostly located in northern and central hinterland, particularly in Alto-Tâmega, Terras de Trás-os-Montes, Douro, Beiras e Serra da Estrela and Beira Baixa. Additionally, a few municipalities within these clusters belong to Alentejo Central and Baixo Alentejo, two provinces with scarce number of fires and burnt area. Box-plots of the DSRp80TBA and DSRp90TBA for the municipalities of each cluster (Figure 9) are consistent with the previous results. Dispersion is considerably higher in the latter than in the former case, especially in clusters 3,7 and 8 . In some municipalities of clusters 7 and 8 , large wildfires, with the ability to exceed FTBA=10\% (Figure 8), start to occur with relatively low values 
of DSRp. Another notable difference is the boxplot medians: for DSRp90TBA they decrease with the ascending number of clusters as expectable, but not for DSRp80TBA, where they increase between cluster 4 and 5, between 6 and 7 , and between 8 and 9.

\subsection{Major drivers}

The spatial distribution of the clusters resembles the general pattern of LULC in Portugal (Figure 11). In general, municipalities with high DSRp90TBA are located in regions of forests while municipalities with lower DSRp90TBA are located in regions where shrublands tend to be predominant. LULC type analysis, made in each cluster, indicates that BA in forests (BAF) is notably higher than shrublands (BAS), in the first five clusters than in the last four clusters (Figure 11, top panel). This means that BAF is higher for clusters with higher DSRp90TBA while BAS is higher for clusters with lower DSRp90TBA. In addition, there is an increase of the fraction of BA in agriculture land associated with the decrease of DSRp90TBA. This amount is larger or very close to $10 \%$ in clusters 6-9 and lower in clusters 1-5. Results show marked evidences between most of coastal and northern/north eastern hinterland municipalities, which present similar DSRp90TBA and, therefore, similar cluster distribution. Highest BAF characterizes the majority of the municipalities with the observed highest DSRp at $90 \%$ of TBA (generally above 85) while the territory with higher BAS is also characterized by lower DSRp90TBA (below 85). These clusters (7-9) also present relatively high percentages of BA in agriculture (mostly between 10 and 20\%). It is also worth mentioning that some municipalities present similar BAF and BAS, although being located in the coastal regions, usually characterized by higher forest cover. Land cover also helps to understand the DSRp80TBA and DSRp90TBA boxplots for each cluster, especially the higher dispersion in the later in comparison with the former (Figure 9). These dissimilarities are especially evident in cluster 8 , which is the cluster with highest BA in shrublands and agriculture (twice the value of clusters $1-5$ ) and less in forest (half the value of clusters 1-5). Additionally, cluster 8 is the one with less burnable area (not shown). The combination of these factors could explain the high dispersion: high BA in shrublands can occur with low DSRp, high BA in agricultural lands is much more likely to occur with high DSRp; and, finally, low burnable areas prevents very large wildfires to occur, even with extreme DSRp. A contingency table permitted to evaluate the influence of vegetation cover in the spatial distribution of the clusters and, therefore, also in DSRp90TBA. Table 1 is based on the results illustrated in Figure 11 and aims to assess if the differences in groups of clusters or in DSRp90TBA can be explained by the BA prevailing in forested areas or in shrubland+agricultural zones. Specifically, it purposes to assess if municipalities of clusters $1-5$, with DSRp90TBA $>90$, have higher BAF (BAF>50\%), and, on the contrary, clusters $7-9$, with DSRp90TBA $<90$, present higher BAS+BAA (BAS+BAA $>50 \%$ ). Results reveal that the number of municipalities of clusters 1-5 and $\mathrm{BAF}>50 \%$ is 4.6 times higher than the number of municipalities in clusters 7-9 and $\mathrm{BAF}>50 \%$. However, the number of municipalities of clusters 7-9 and BAS+BAA $>50 \%$ is 1.3 higher than the number of municipalities of clusters $1-5$ and BAS+BAA $>50 \%$. Consequently, the OA $(71 \%)$, UA $(71 \%-70 \%)$ and PA $(82 \%-55 \%)$ reveal moderate to high accuracy. The BAS+BAA $>50 \%$ threshold is probably a too demanding criterion for DSRp $90 \mathrm{TBA}=90$ limit, as shrublands and agriculture land cover will also burn with higher DSRp in a large number of municipalities. For forests (BAF $>50 \%)$, the accuracy is better, i.e., this threshold has been accurate in more than four times of the municipalities that were incorrectly classified. The $\chi 2$ test results indicate that we can claim that the samples are independent, with an error risk 
of about 4e-06. The Cohen's Kappa test allow to conclude a fair agreement $(\kappa=0.3828)$ and reject null hypothesis: observed agreement is not accidental. The $\Phi$ and $\mathrm{C}$ tests also corroborated that variables are dependent, with similar values, 0.3903 and 0.3636 , respectively.

\section{Discussion}

It is important to discuss some methodological options. Only wildfires occurred in the extended summer period, from 15th May to 31st October, were studied because of two main reasons: (i) BA within this period accounts for $97.5 \%$ of TBA, assuming only large fires; and, (ii) the secondary peak of fire incidence in Portugal occurs in late winter early spring, with low DSR values and depends more on drought than on temperature (Amraoui et al., 2015; Calheiros, et al., 2020). Only large wildfires (BA>100 ha), similarly defined by the Portuguese forest authorities (ICNF), have been included also for two reasons. First, wildfires in Portugal are mainly (99.4\%) caused by humans, by negligence (about one quarter of total number of wildfires with known cause) and intentionally (about three quarters), associated to the use of fire, accident and structural/land use (Parente et al., 2018) i.e., small wildfires can occur with relatively low DSR. Second, mainland Portugal registers a very large number of small wildfires but they account only for a small amount of TBA. For example, wildfires with BA $>100$ ha are just about $1 \%$ of all wildfires, but account for $75 \%$ of total burnt area (Pereira et al., 2011). LULC data can limit the analysis and affect the obtained results. LULC changed during the 19 years $(2001$ - 2019) of the study period in many locations, including in the BA polygons. Effectively, Meneses et al., (2018) observed that the main land use changes, for the 1990-2012 period, are related to reductions in forests and agricultural areas, together with increases in urban areas, with relative small changes between 2000-2006 and 2006-2012 periods. Therefore, LULC changes do not significantly affect the findings, knowing that we only use LULC data for one year/inventory to assess wildfire selectivity. Understory vegetation is also a very important factor in fire vulnerability, spread and intensity (Fonseca and Duarte, 2017; Espinosa et al., 2019). Consequently, wildfires only tend to occur and spread in managed forests with very high DSR, higher than in unmanaged forests (Fernandes, Guiomar and Rossa, 2019). However, land use data does not include forest management information. Despite the small fraction of managed forested areas, roughly 20\%, as estimated by Beighley and Hyde, (2018), this lack of information can influence our results, particularly in the municipalities with a significant share of managed forest area. Results (Figure 2 and Figure 3) suggest that DSR90p is a suitable threshold for entire territory of mainland Portugal which is in line with previous studies (Carvalho et al., 2008; Bedia, Herrera and Guti, 2012; Fernandes, 2019; Silva et al., 2019). The importance of extreme weather for the occurrence of large wildfires in Portugal have been already pointed out in several studies (Trigo et al., 2006; J. Parente et al., 2018; Parente et al., 2019; T. Calheiros, J.P. Nunes and Pereira, 2020; Calheiros, Pereira and Nunes, 2021). Large wildfires (BA>100 ha) are essentially dependent on the existence of extreme fire weather and small and medium size wildfires are much more dependent on the daily and annual (weather/vegetation) cycles (Telesca and Pereira, 2010). However, analysis performed at finer level (Figure 4) discloses interesting deviations, namely differences between coastal areas and the hinterland municipalities. Most of the inland municipalities in the northeast (Alto Tâmega, Terras de Trás-os-Montes, Douro and northern 
with DSRp<80, while large wildfires occur in coastal and some mountainous municipalities (parts of Área Metropolitana do Porto, Viseu Dão-Lafões, Região de Coimbra, Beira Baixa and Região de Leiria) with DSR=DSR90p. Differences in DSRp throughout the territory are expected due to distinct characteristic factors, including climate and landscape features. Mainland Portugal has two slightly different types of temperate (group C) climate, namely Csb (dry and warm summer) in the north and Csa (dry and hot summer) in the south, which promote different fire regimes in these two regions (Parente, Pereira and Tonini, 2016). In fact, patterns of DSRp80TBA or DSRp90TBA (Figure 4) strongly resemble the spatial distribution of the type of climates in Portugal (see Fig. 1 of AEMET, (2011)), in the sense that regions with higher (lower) DSRp80TBA or DSRp90TBA present Csb (Csa) type of climate. LULC is also an important wildfire factor in Portugal (Barros and Pereira, 2014; Pereira, Aranha and Amraoui, 2014; Parente and Pereira, 2016; Leuenberger et al., 2018; Tonini, Parente and Pereira, 2018). Therefore, it is not surprising the high similarity between the spatial patterns of DSRp80TBA or DSRp90TBA and the LULC maps for Portugal (e.g., see Figure 4 of (Parente and Pereira, 2016)). Other wildfire-related landscape features were assessed to explain the heterogeneity of DSRp80TBA and DSRp90TBA maps (Figure 4). The ratio Forest/Shrublands BNA shows higher BNA in forests in most of the territory but the ratio Forest/Shrublands TBA reveals higher TBA in shrublands, especially in regions of lower DSRp80TBA and DSRp90TBA. We did not analyze different types of forest or shrublands separately. Land cover proneness to wildfires is higher for shrublands and pine forests than for annual crops, mixed forests and evergreen oak woodlands (Barros and Pereira, 2014; Pereira, Aranha and Amraoui, 2014). Those authors also observed that, as wildfire size increases, selectivity decreases for all land cover types. These findings may be a consequence of the different impacts of the fire weather on the different land cover types which motivates further research on the role of vegetation in the spatial distribution of DSRp associated with a larger fraction of TBA. As expected, the spatial distribution of the clusters (Figure 7) is also very similar to the DSRp80TBA and DSRp90TBA maps (Figure 4), especially the marked differences between the coastal and north-eastern and south-central hinterland municipalities. The curves of DSRp vs FTBA for the clusters show decreasing derivatives and increasing variability with the decrease in the DSR, which means a trend for large wildfires to occur with less extreme weather conditions and greater variability between the municipalities of each cluster. The cluster analysis based on the DSRp vs FTBA curves aimed to find groups of municipalities with similar fire-weather relation. Contingency tables account for the municipalities of two distinct groups of clusters in terms of DSR. Contingency tables, accuracy and statistical tests led us to conclude that vegetation types, particularly forest and shrublands, influences the spatial distribution of DSRp observed in Portugal. In addition to the type of climate, the different vegetation cover justifies the spatial distribution of DSRp within mainland Portugal and, therefore, explains clusters' dissimilarities. On one hand, DSR extremes are strongly influenced by long lasting severe droughts (before and during fire season), heatwaves (during fire season), or both. Heat waves and droughts are important extreme weather/climate events, promoting wildfires occurrence and spread, and, therefore, for TBA (Russo et al., 2017; Parente et al., 2018; Parente et al., 2019). On the other hand, shrublands are more likely to suffer from droughts than forests. As observed by Gouveia et al., (2012), during drought shrublands presented higher levels of dryness, whereas broad-leaved forests exhibited lower water stress. Coniferous forests are more resistant to short-term droughts than broad-leaved forests, because of their decreased vulnerability to xylem cavitation (Allen et al., 2010). Consequently, forests tend to burn only under extreme DSR values, typically caused by simultaneous drought and heatwave, while shrublands (and 
also agricultural areas) can burn with lower DSRp. These facts can be additionally justified by biological features. In the Mediterranean region, precipitation is the main constrain to photosynthesis and growth (Pereira et al., 2007). This is particularly critical for shallow rooted species, like those of the herbaceous vegetation and some shrub species, which are unable to access to groundwater. It is less critical for the deeply rooted species such as cork oak, and other drought resistant Mediterranean species (Cerasoli, Costa e Silva and Silva, 2016).

\section{Conclusions}

Results reveal that the DSR90p is an adequate threshold for extreme burnt area in Continental Portugal. However, at the municipality level, some important differences appear among DSRp thresholds that explain 90 and 80\% of the TBA. Cluster analysis shows that these differences justified the existence of several statistically significant clusters. Generally, municipalities where large wildfires occur with high or very high DSRp values are located in north and central coastal areas, especially in mountainous regions (parts of Área Metropolitana do Porto, Região de Aveiro and Região de Leiria), central hinterland mountainous areas (portions of Viseu Dão-Lafões, Região de Coimbra and Beira Baixa) and in Algarve. In contrast, clusters where large fires where registered with low DSRp values mostly appear in north-eastern (particularly in Douro and Terras de Trás-os-Montes). The type of climate and vegetation cover explain the clusters' distribution pattern and the relationship between DSRp and total BA. In fact, large wildfires tend to occur mostly in forests with very high or extreme DSRp while, in shrublands, with relatively lower DSRp. The relationship between vegetation cover and DSRp was statistically validated with the contingency tables and statistical tests. Results indicate an overall accuracy of $71 \%$ and a statistical relationship between independent variables. BNA highest values are visible in the mountainous regions between the coastal and hinterland municipalities and, at the contrary, lowest values are present in urban coastal municipalities and in some hinterland regions. BNA also has the ability to influence DSRp vs FTBA curve in the municipalities and to explain the high variability in DSRp in the clusters. In summary, this work disclosed that the usual 90th percentile of DSR is a good indicator for extreme burnt areas in mainland Portugal. However, at higher resolution, this threshold present regional variations that should be taken into account, namely for fire danger, firefighting plans, etc. These findings could help firefighters and civil protection in prevention and combat planning, more importantly knowing the importance and operational use of DSR in Portugal. Climate type and vegetation cover explain the DSRp spatial distribution dissimilarities, highlighting that landscape and forest management are key factor for the adaptation to future climate change.

Data availability. This research was developed using three public data sources. The meteorological variables were obtained from the fifth generation of ECMWF atmospheric reanalyses of the global climate (ERA5-Land) dataset (Copernicus Climate Change Service (C3S), 2017). Land use and land cover data were provided by Portuguese national authorities (DGT, 2019), and the wildfire database from the 
https://doi.org/10.5194/nhess-2021-173

Preprint. Discussion started: 30 June 2021

(c) Author(s) 2021. CC BY 4.0 License.

(c) (i)

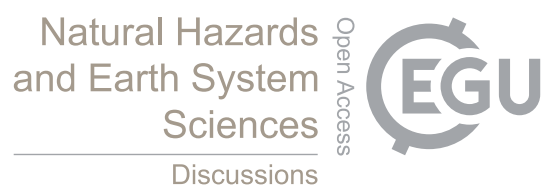

\section{APPENDIX}

In this section we demonstrate results that were not fundamental for this manuscript. The Number of fires in Portugal (Figure 1), in each analysed municipality, were assessed. The distribution of the number of wildfires, between 2001 and 2019, discloses a notable contrast between north and southern provinces (the last ones considered as Alto Alentejo, Alentejo Central, Alentejo Litoral, Baixo Alentejo and Algarve). Wildfires were more frequent in the extreme northwest (Alto Minho and Alto Tâmega) and in some municipalities located in Beiras e Serra da Estrela. Wildfire frequency is much lower in south and in most of the western coast.

Author contributions. TC developed the code to analyse the data, produced the results and plots, and wrote the original draft of the manuscript. $\mathrm{AB}$ contributed to the supervision, the code to analyse data and produce plots, and also to the writing. JNS contributed to the supervision, methodology and writing. MP contributed to the supervision, production of plots and writing. JPN contributed to the supervision and writing. All authors contributed to the conceptualization and methodology of this research.

Competing interests. The authors declare that they have no conflict of interest.

Acknowledgements. This work was funded by the Portuguese Fundação para a Ciência e a Tecnologia through the PhD fellowship attributed to T Calheiros (PD/BD/128173/2016). Additional funding was obtained through the individual research grant attributed to JP Nunes (IF/00586/2015), research project FRISCO (PCIF/MPG/0044/2018), and research unit funding attributed to the CE3C, CITAB and Forest Research Centre (CEF) research centres (UIDB/00329/2020,UIDB/04033/2020 and IDB/00239/2020, respectively). 


\section{References}

Alberg, A. J., Park, J. W., Hager, B. W., Brock, M. V. and Diener-West, M.: The use of "overall accuracy" to evaluate the validity of screening or diagnostic tests, J. Gen. Intern. Med., 19(5 PART 1), 460-465, doi:10.1111/j.1525-1497.2004.30091.x, 2004.

Allen, C. D., Macalady, A. K., Chenchouni, H., Bachelet, D., McDowell, N., Vennetier, M., Kitzberger, T., Rigling, A., Breshears, D. D., Hogg, E. H. (Ted., Gonzalez, P., Fensham, R., Zhang, Z., Castro, J., Demidova, N., Lim, J. H., Allard, G., Running, S. W., Semerci, A. and Cobb, N.: A global overview of drought and heat-induced tree mortality reveals emerging climate change risks for forests, For. Ecol. Manage., 259(4), 660-684, doi:10.1016/j.foreco.2009.09.001, 2010.

Amraoui, M., Pereira, M. G., Dacamara, C. C. and Calado, T. J.: Atmospheric conditions associated with extreme fi re activity in the Western Mediterranean region, Sci. Total Environ., 524-525, 32-39, doi:10.1016/j.scitotenv.2015.04.032, 2015.

Instituto da Conservação da Natureza e das Florestas, [online] Available from: http://www2.icnf.pt/portal/florestas/dfci/inc/mapas, 2020. Barros, A. M. G. and Pereira, J. M. C.: Wildfire selectivity for land cover type: Does size matter?, PLoS One, 9(1), doi:10.1371/journal.pone.0084760, 2014. Bedia, J., Herrera, S. and Guti, J. M.: Sensitivity of fire weather index to different reanalysis products in the Iberian Peninsula, Nat. Hazards Earth Syst. Sci., 699-708, doi:10.5194/nhess-12-699-2012, 2012.

Beighley, M. and Hyde, A. C.: Portugal Wildfire Management in a New Era: Assessing Fire Risks , Resources and Reforms, , (February), 52, 2018. Benali, A., Russo, A., Sá, A. C. L., Pinto, R. M. S., Price, O., Koutsias, N. and Pereira, J. M. C.: Determining fire dates and locating ignition points with satellite data, Remote Sens., 8(4), doi:10.3390/rs8040326, 2016.

Calheiros, T., Nunes, J. P. and Pereira, M. G.: Recent evolution of spatial and temporal patterns of burnt areas and fire weather risk in the Iberian Peninsula, Agric. For. Meteorol., 287, 107923, doi:10.1016/J.AGRFORMET.2020.107923, 2020.

Calheiros, T., Pereira, M. G. and Nunes, J. P.: Assessing impacts of future climate change on extreme fire weather and pyro-regions in Iberian Peninsula, Sci. Total Environ., 754, 142233, doi:10.1016/j.scitotenv.2020.142233, 2021.

Carmo, M., Moreira, F., Casimiro, P. and Vaz, P.: Land use and topography influences on wildfire occurrence in northern Portugal, Landsc. Urban Plan., 100(1-2), 169-176, doi:10.1016/j.landurbplan.2010.11.017, 2011.

Carvalho, A., Flannigan, M. D., Logan, K., Miranda, A. I. and Borrego, C.: Fire activity in Portugal and its relationship to weather and the Canadian Fire Weather Index System, Int. J. Wildl. Fire, 17(3), 328-338, doi:10.1071/WF07014, 2008.

Cerasoli, S., Costa e Silva, F. and Silva, J. M. N.: Temporal dynamics of spectral bioindicators evidence biological and ecological differences among functional types in a cork oak open woodland, Int. J. Biometeorol., 60(6), 813-825, doi:10.1007/s00484-015-1075-x, 2016.

Cohen, J.: A Coefficient of Agreement for Nominal Scales, Educ. Psychol. Meas., 20(1), 37-46, doi:10.1177/001316446002000104, 1960.

Congalton, R. G.: Accuracy assessment and validation of remotely sensed and other spatial information, Int. J. Wildl. Fire, 10(3-4), 321-328, doi:10.1071/wf01031, 2001.

Copernicus Climate Change Service (C3S): ERA5: Fifth generation of ECMWF atmospheric reanalyses of the global climate, Copernicus Clim. Chang. Serv. Clim. Data Store [online] Available from: https://cds.climate.copernicus.eu/cdsapp\#!/dataset/reanalysis-era5land?tab=overview, 2017.

David, F. N. and Cramer, H.: Mathematical Methods of Statistics., Biometrika, 34(3/4), 374, doi:10.2307/2332454, 1947.

430 Duane, A. and Brotons, L.: Synoptic weather conditions and changing fire regimes in a Mediterranean environment, Agric. For. Meteorol., 253-254(January), 190-202, doi:10.1016/j.agrformet.2018.02.014, 2018.

Elia, M., Lovreglio, R., Ranieri, N. A., Sanesi, G. and Lafortezza, R.: Cost-effectiveness of fuel removals in mediterraneanwildland-urban interfaces threatened by wildfires, Forests, 7(149), 1-11, doi:10.3390/f7070149, 2016. 
https://doi.org/10.5194/nhess-2021-173

Preprint. Discussion started: 30 June 2021

(c) Author(s) 2021. CC BY 4.0 License.

Espinosa, J., Palheiro, P., Loureiro, C., Ascoli, D., Esposito, A. and Fernandes, P. M.: Fire-severity mitigation by prescribed burning assessed from fire-treatment encounters in maritime pine stands, Can. J. For. Res., 49(2), 205-211, doi:10.1139/cjfr-2018-0263, 2019.

European Environment Agency: Copernicus Land Monitoring Service, Copernicus L. Monit. Serv. - EU-DEM [online] Available from: https://www.eea.europa.eu/data-and-maps/data/copernicus-land-monitoring-service-eu-dem (Accessed 17 March 2021 ), 2021.

Fernandes, P. M.: Variation in the canadian fire weather index thresholds for increasingly larger fires in Portugal, Forests, 10(10), doi:10.3390/f10100838, 2019.

440 Fernandes, P. M., Monteiro-Henriques, T., Guiomar, N., Loureiro, C. and Barros, A. M. G.: Bottom-Up Variables Govern Large-Fire Size in Portugal, Ecosystems, 19(8), 1362-1375, doi:10.1007/s10021-016-0010-2, 2016.

Fernandes, P. M., Guiomar, N. and Rossa, C. G.: Analysing eucalypt expansion in Portugal as a fire-regime modifier, Sci. Total Environ., 666, 79-88, doi:10.1016/j.scitotenv.2019.02.237, 2019. Ferreira-Leite, F., Bento-Gonçalves, A., Vieira, A., Nunes, A. and Lourenço, L.: Incidence and recurrence of large forest fires in mainland Portugal, Nat. Hazards, 84(2), 1035-1053, doi:10.1007/s11069-016-2474-y, 2016.

Fonseca, T. F. and Duarte, J. C.: A silvicultural stand density model to control understory in maritime pine stands, IForest, 10(5), 829-836, doi:10.3832/ifor2173-010, 2017.

Gouveia, C. M., Bastos, A., Trigo, R. M. and Dacamara, C. C.: Drought impacts on vegetation in the pre- and post-fire events over Iberian Peninsula, Nat. Hazards Earth Syst. Sci., 12(10), 3123-3137, doi:10.5194/nhess-12-3123-2012, 2012.

Greenwood, P. E. and Nikulin, M. S.: A Guide to Chi-Squared Testing, , 1-2, 1996.

Groot, W. J. De: Interpreting the Canadian Forest Fire Weather Index (FWI) System, Fourth Cent. Reg. Fire Weather Comm. Sci. Tech. Semin., Proceeding, 3-14 [online] Available from: http://scholar.google.com/scholar?hl=en\&btnG=Search\&q=intitle:Interpreting+the+canadian+forest+fire+weather+index+(FWI)+system\#0, 1987.

Instituto de Meteorologia de Portugal and Agência Estatal de Meteorologia de Espanha: Atlas climático ibérico: Temperatura do ar e precipitação (1971-2000)., 2011.

Jimenez-Ruano, A., Rodrigues, M., Jolly, W. M. and de la Riva, J.: The role of short-term weather conditions in temporal dynamics of fire regime features in mainland Spain, J. Environ. Manage., In press(September), 1-12, doi:10.1016/j.jenvman.2018.09.107, 2018.

Jones, N., de Graaff, J., Rodrigo, I. and Duarte, F.: Historical review of land use changes in Portugal (before and after EU integration in 1986) and their implications for land degradation and conservation, with a focus on Centro and Alentejo regions, Appl. Geogr., 31(3), 1036-1048, doi:10.1016/j.apgeog.2011.01.024, 2011.

Kanevski, M. and Pereira, M. G.: Local fractality: The case of forest fires in Portugal, Phys. A Stat. Mech. its Appl., 479, 400-410, doi:10.1016/j.physa.2017.02.086, 2017.

Leuenberger, M., Parente, J., Tonini, M., Pereira, M. G. and Kanevski, M.: Wildfire susceptibility mapping: Deterministic vs. stochastic approaches, Environ. Model. Softw., 101, 194-203, doi:10.1016/j.envsoft.2017.12.019, 2018.

Lloret, F., Calvo, E., Pons, X. and Díaz-Delgado, R.: Wildfires and Landscape Patterns in the Eastern Iberian Peninsula, Landsc. Ecol., 17(8), 745-759, doi:https://doi.org/10.1023/A:1022966930861, 2002.

McHugh, M. L.: Lessons in biostatistics interrater reliability: the kappa statistic, Biochem. Medica, 22(3), 276-282, Available from: https://hrcak.srce.hr/89395, 2012.

470 Meneses, B. M., Reis, E. and Reis, R.: Assessment of the recurrence interval of wildfires in mainland portugal and the identification of affected luc patterns, J. Maps, 14(2), 282-292, doi:10.1080/17445647.2018.1454351, 2018a. 
https://doi.org/10.5194/nhess-2021-173

Preprint. Discussion started: 30 June 2021

(c) Author(s) 2021. CC BY 4.0 License.

Meneses, B. M., Reis, E., Vale, M. J. and Reis, R.: Modelling land use and land cover changes in Portugal: A multi-scale and multi-temporal approach, Finisterra, 53(107), 3-26, doi:10.18055/finis12258, 2018b.

Moreira, F., Viedma, O., Arianoutsou, M., Curt, T., Koutsias, N., Rigolot, E., Barbati, A., Corona, P., Vaz, P., Xanthopoulos, G. and Mouillot, F.: Landscape e wild fi re interactions in southern Europe: Implications for landscape management, J. Environ. Manage., 92(10), 2389-2402, doi:10.1016/j.jenvman.2011.06.028, 2011.

Moreno, M. V., Conedera, M., Chuvieco, E. and Pezzatti, G. B.: Fire regime changes and major driving forces in Spain from 1968 to 2010 , Environ. Sci. Policy, 37, 11-22, doi:10.1016/j.envsci.2013.08.005, 2014.

Nunes, A. N.: Regional variability and driving forces behind forest fires in Portugal an overview of the last three decades (1980-2009), Appl. Geogr., 34(March), 576-586, doi:10.1016/j.apgeog.2012.03.002, 2012.

Nunes, A. N., Lourenço, L. and Meira, A. C. C.: Exploring spatial patterns and drivers of forest fires in Portugal (1980-2014), Sci. Total Environ., 573, 1190-1202, doi:10.1016/j.scitotenv.2016.03.121, 2016.

Nunes, S. A., Dacamara, C. C., Turkman, K. F., Calado, T. J., Trigo, R. M. and Turkman, M. A. A.: Wildland fire potential outlooks for Portugal using meteorological indices of fire danger, Nat. Hazards Earth Syst. Sci., 19(7), 1459-1470, doi:10.5194/nhess-19-1459-2019, 2019.

Oliveira, T. M., Guiomar, N., Baptista, F. O., Pereira, J. M. C. and Claro, J.: Is Portugal's forest transition going up in smoke?, Land use policy, 66(May), 214-226, doi:10.1016/j.landusepol.2017.04.046, 2017.

Parente, J. and Pereira, M. G.: Structural fire risk: The case of Portugal, Sci. Total Environ., 573, 883-893, doi:10.1016/j.scitotenv.2016.08.164, 2016.

490 Parente, J., Pereira, M. G. and Tonini, M.: Space-time clustering analysis of wildfires: The influence of dataset characteristics, fire prevention policy decisions, weather and climate, Sci. Total Environ., 559, 151-165, doi:10.1016/j.scitotenv.2016.03.129, 2016.

Parente, J., Pereira, M. G., Amraoui, M. and Fischer, E. M.: Heat waves in Portugal: Current regime, changes in future climate and impacts on extreme wildfires, Sci. Total Environ., 631-632, 534-549, doi:10.1016/j.scitotenv.2018.03.044, $2018 \mathrm{a}$.

Parente, J., Pereira, M. G., Amraoui, M. and Tedim, F.: Negligent and intentional fires in Portugal: Spatial distribution characterization, Sci.

Total Environ., 624, 424-437, doi:10.1016/j.scitotenv.2017.12.013, 2018b.

Parente, J., Amraouia, M., Menezes, I. and Pereira, M. G.: Drought in Portugal: Current regime, comparison of indices and impacts on extreme wildfires, Sci. Total Environ., 685, 150-173, doi:10.1016/j.scitotenv.2019.05.298, 2019.

Pausas, J. G. and Fernández-Muñoz, S.: Fire regime changes in the Western Mediterranean Basin: From fuel-limited to drought-driven fire regime, Clim. Change, 110(1-2), 215-226, doi:10.1007/s10584-011-0060-6, 2012.

500 Pausas, J. G. and Vallejo, V. R.: The role of fire in European Mediterranean ecosystems, in Remote Sensing of Large Wildfires, pp. 3-16, Springer Berlin Heidelberg, Berlin, Heidelberg., 1999.

Pereira, J. S., Chaves, M. M., Caldeira, M. C. and Correia, A. V.: Water Availability and Productivity, Plant Growth Clim. Chang., (December 2017), 118-145, doi:10.1002/9780470988695.ch6, 2007.

Pereira, M., Calado, T., DaCamara, C. and Calheiros, T.: Effects of regional climate change on rural fires in Portugal, Clim. Res., 57(3), 187-200, doi:10.3354/cr01176, 2013.

Pereira, M. G., Trigo, R. M., da Camara, C. C., Pereira, J. M. C. and Leite, S. M.: Synoptic patterns associated with large summer forest fires in Portugal, Agric. For. Meteorol., 129(1-2), 11-25, doi:10.1016/j.agrformet.2004.12.007, 2005.

Pereira, M. G., Malamud, B. D., Trigo, R. M. and Alves, P. I.: The history and characteristics of the 1980 - 2005 Portuguese rural fire database, Nat. Hazards Earth Syst. Sci., (Table 1), 3343-3358, doi:10.5194/nhess-11-3343-2011, 2011. 
510 Pereira, M. G., Aranha, J. and Amraoui, M.: Land cover fire proneness in Europe, For. Syst., 23(3), 598-610, 2014.

Pereira, M. G., Caramelo, L., Orozco, C. V., Costa, R. and Tonini, M.: Space-time clustering analysis performance of an aggregated dataset: The case of wildfires in Portugal, Environ. Model. Softw., 72, 239-249, doi:10.1016/j.envsoft.2015.05.016, 2015.

Rodrigues, M., Trigo, R. M., Vega-García, C. and Cardil, A.: Identifying large fire weather typologies in the Iberian Peninsula, Agric. For. Meteorol., 280(November 2019), 107789, doi:10.1016/j.agrformet.2019.107789, 2020.

Romano, N. and Ursino, N.: Forest fire regime in a mediterranean ecosystem: Unraveling the mutual interrelations between rainfall seasonality, soil moisture, drought persistence, and biomass dynamics, Fire, 3(3), 1-20, doi:10.3390/fire3030049, 2020.

Ruffault, J., Curt, T., Martin-Stpaul, N. K., Moron, V. and Trigo, R. M.: Extreme wildfire events are linked to global-change-type droughts in the northern Mediterranean, Nat. Hazards Earth Syst. Sci., 18(3), 847-856, doi:10.5194/nhess-18-847-2018, 2018.

Russo, A., Gouveia, C. M., Páscoa, P., DaCamara, C. C., Sousa, P. M. and Trigo, R. M.: Assessing the role of drought events on wildfires in the Iberian Peninsula, Agric. For. Meteorol., 237-238, 50-59, doi:10.1016/j.agrformet.2017.01.021, 2017.

San-Miguel-Ayanz, J., Durrant, T., Boca, R., Maianti, P., Liberta‘, G., Artes Vivancos, T., Jacome Felix Oom, D., Branco, A., De Rigo, D., Ferrari, D., Pfeiffer, H., Grecchi, R., Nuijten, D. and Leray, T.: Forest Fires in Europe, Middle East and North Africa 2019, , doi:10.2760/468688, 2020.

Scotto, M. G., Gouveia, S., Carvalho, A., Monteiro, A., Martins, V., Flannigan, M. D., San-Miguel-Ayanz, J., Miranda, A. I. and Borrego, C.: Area burned in Portugal over recent decades: An extreme value analysis, Int. J. Wildl. Fire, 23(6), 812-824, doi:10.1071/WF13104, 2014.

Silva, J. M. N., Moreno, M. V., Page, Y. Le, Oom, D., Bistinas, I. and Pereira, J. M. C.: Spatiotemporal trends of area burnt in the Iberian Peninsula , 1975 - 2013, Reg. Environ. Chang., 515-527, 2019.

Sousa, P. M., Trigo, R. M., Pereira, M. G., Bedia, J. and Gutiérrez, J. M.: Different approaches to model future burnt area in the Iberian Peninsula, Agric. For. Meteorol., 202, 11-25, doi:10.1016/j.agrformet.2014.11.018, 2015.

Stamou, Z., Xystrakis, F. and Koutsias, N.: The role of fire as a long-term landscape modifier: Evidence from long-term fire observations (1922-2000) in Greece, Appl. Geogr., 74, 47-55, doi:10.1016/j.apgeog.2016.07.005, 2016.

Sutanto, S. J., Vitolo, C., Di Napoli, C., D’Andrea, M. and Van Lanen, H. A. J.: Heatwaves, droughts, and fires: Exploring compound and cascading dry hazards at the pan-European scale, Environ. Int., 134(January), 105276, doi:10.1016/j.envint.2019.105276, 2020.

Telesca, L. and Pereira, M. G.: Time-clustering investigation of fire temporal fluctuations in Portugal, Nat. Hazards Earth Syst. Sci., 10(4), 661-666, doi:10.5194/nhess-10-661-2010, 2010.

Território, D.-G. do: Especificações técnicas da Carta de Uso e Ocupação do Solo (COS) de Portugal Continental para $2018,2019$.

Tonini, M., Parente, J. and Pereira, M. G.: Global assessment of rural-urban interface in Portugal related to land cover changes, Nat. Hazards Earth Syst. Sci., 18(6), 1647-1664, doi:10.5194/nhess-18-1647-2018, 2018.

540 Trigo, R. M., Pereira, J. M. C., Pereira, M. G., Mota, B., Calado, T. J., Dacamara, C. C. and Santo, F. E.: Atmospheric conditions associated with the exceptional fire season of 2003 in Portugal, Int. J. Climatol., 26(13), 1741-1757, doi:10.1002/joc.1333, 2006.

Trigo, R. M., Sousa, P. M., Pereira, M. G., Rasilla, D. and Gouveia, C. M.: Modelling wildfire activity in Iberia with different atmospheric circulation weather types, Int. J. Climatol., 36(7), 2761-2778, doi:10.1002/joc.3749, 2016.

Turco, M., Rosa-Cánovas, J. J., Bedia, J., Jerez, S., Montávez, J. P., Llasat, M. C. and Provenzale, A.: Exacerbated fires in Mediterranean 018-06358-z, 2018. 
https://doi.org/10.5194/nhess-2021-173

Preprint. Discussion started: 30 June 2021

(c) Author(s) 2021. CC BY 4.0 License.

(c) (1)

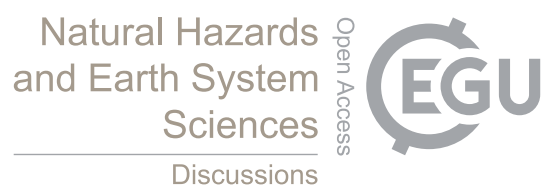

Turco, M., Jerez, S., Augusto, S., Tarín-Carrasco, P., Ratola, N., Jiménez-Guerrero, P. and Trigo, R. M.: Climate drivers of the 2017 devastating fires in Portugal, Sci. Rep., 9(1), doi:10.1038/s41598-019-50281-2, 2019.

Viegas, D. X., Bovio, G., Ferreira, A., Nosenzo, A. and Sol, B.: Comparative study of various methods of fire danger evaluation in southern

Europe, Int. J. Wildl. Fire, 9(4), 235, doi:10.1071/WF00015, 1999.

Vieira, I., Russo, A. and Trigo, R. M.: Identifying local-scale weather forcing conditions favorable to generating Iberia's largest fires, Forests, 11(5), 1-14, doi:10.3390/F11050547, 2020.

Vilar, L., Camia, A., San-Miguel-Ayanz, J. and Martín, M. P.: Modeling temporal changes in human-caused wildfires in Mediterranean Europe based on Land Use-Land Cover interfaces, For. Ecol. Manage., 378, 68-78, doi:10.1016/j.foreco.2016.07.020, 2016.

555 Van Wagner, C. . and Pickett, T. L.: Equations and fortran IV program for the 1976 metric version of the forest fire weather index, 1975. Van Wagner, C. E.: Development and structure of the Canadian Forest Fire Weather Index system., 1987. 


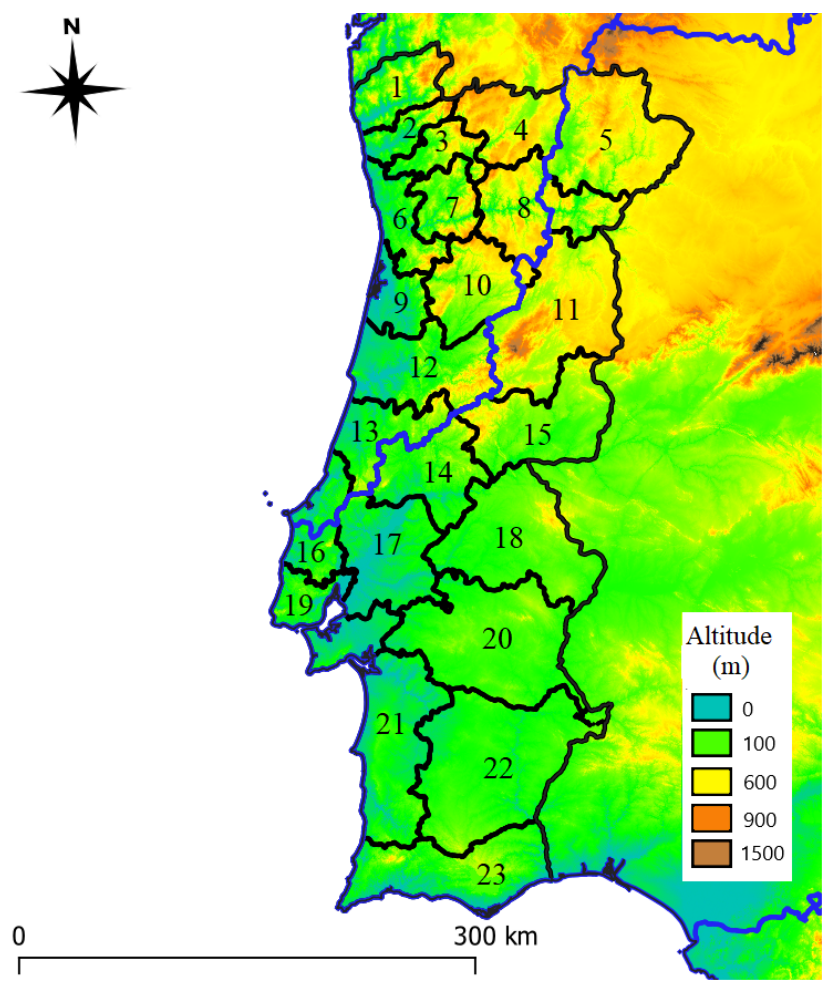

Figure 1. Mainland Portugal topography and NUTSIII provinces: Alto Minho(1), Cávado(2), Ave(3), Alto Tâmega(4), Terras de Trás-osMontes(5), Área Metropolitana do Porto(6), Tâmega e Sousa(7), Douro(8), Região de Aveiro(9), Viseu Dão-Lafões(10), Beiras e Serra da Estrela(11), Região de Coimbra(12), Região de Leiria(13), Médio-Tejo(14), Beira Baixa(15), Oeste(16), Lezíria do Tejo(17), Alto Alentejo(18), Área Metropolitana de Lisboa(19), Alentejo Central(20), Alentejo Litoral(21), Baixo Alentejo(22) and Algarve(23). Adapted from European Environment Agency (2021). Pyro-regions limits from Calheiros, J. P. Nunes and Pereira, (2020), for comparison purposes, were also added, at blue: NW pyro-region is located in northwestern Portugal and SW pyro-region in southwestern and eastern of the country. 
https://doi.org/10.5194/nhess-2021-173

Preprint. Discussion started: 30 June 2021

(c) Author(s) 2021. CC BY 4.0 License.

(c) (i)
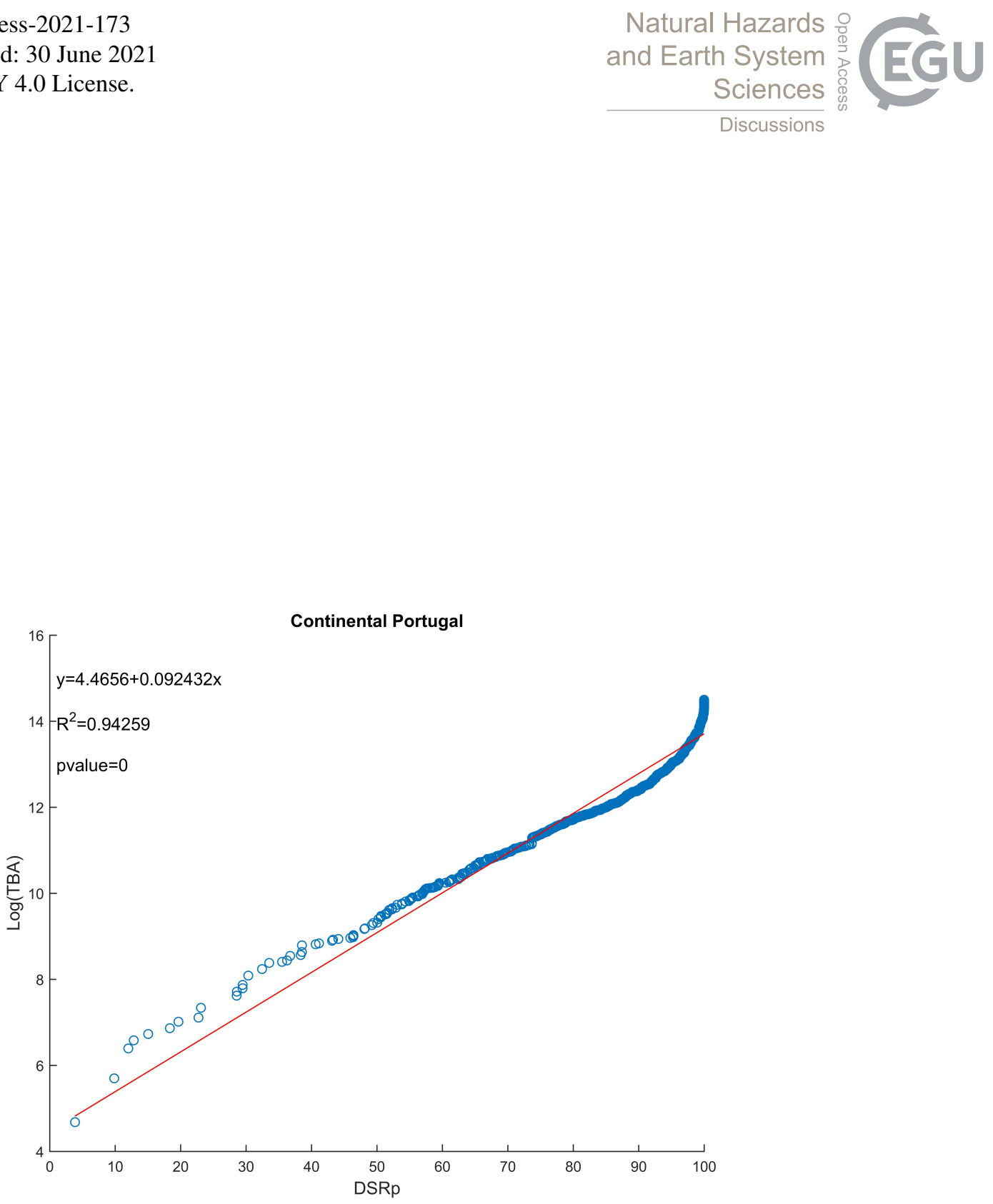

Figure 2. Scatterplot (blue circles) of the decimal logarithm of the total burnt area $(\log (\mathrm{TBA}))$ vs DSR percentile (DSRp), considering the fires with an area larger than 100 ha that occurred between May 15 and October 31, in the $2001-2019$ period. Best fit (red line), respective equation, r-square and p-value are also presented. 
https://doi.org/10.5194/nhess-2021-173

Preprint. Discussion started: 30 June 2021

(c) Author(s) 2021. CC BY 4.0 License.

(c) (i)
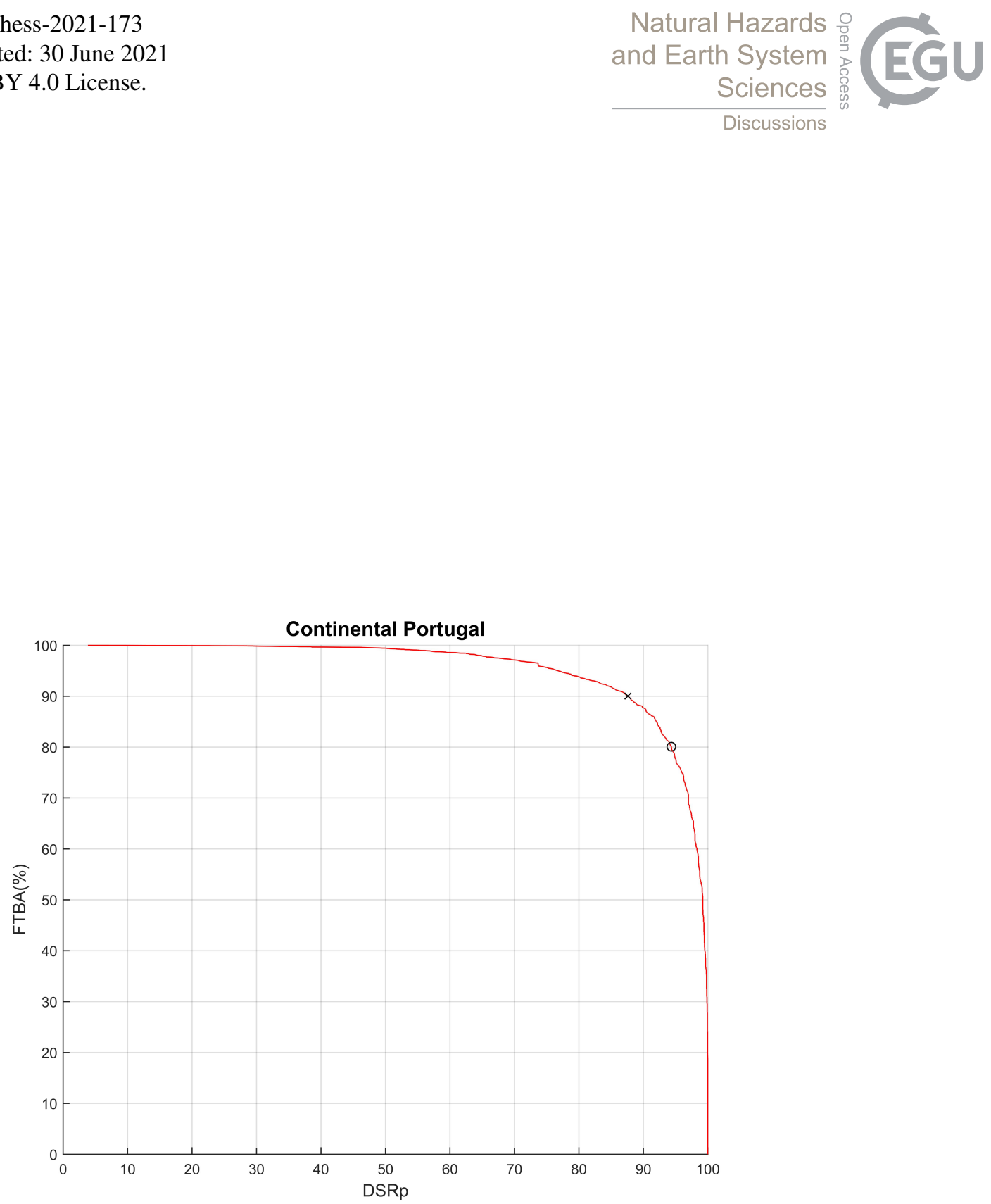

Figure 3. Fraction of total burnt area (FTBA) vs DSR percentile (DSRp), computed for mainland Portugal, in the $2001-2019$ period. The circle (cross) is the DSRp when the FTBA reaches $80 \%$ (90\%). 
https://doi.org/10.5194/nhess-2021-173

Preprint. Discussion started: 30 June 2021

(c) Author(s) 2021. CC BY 4.0 License.

\section{Natural Hazards 웅 and Earth System Sciences \\ Discussions}
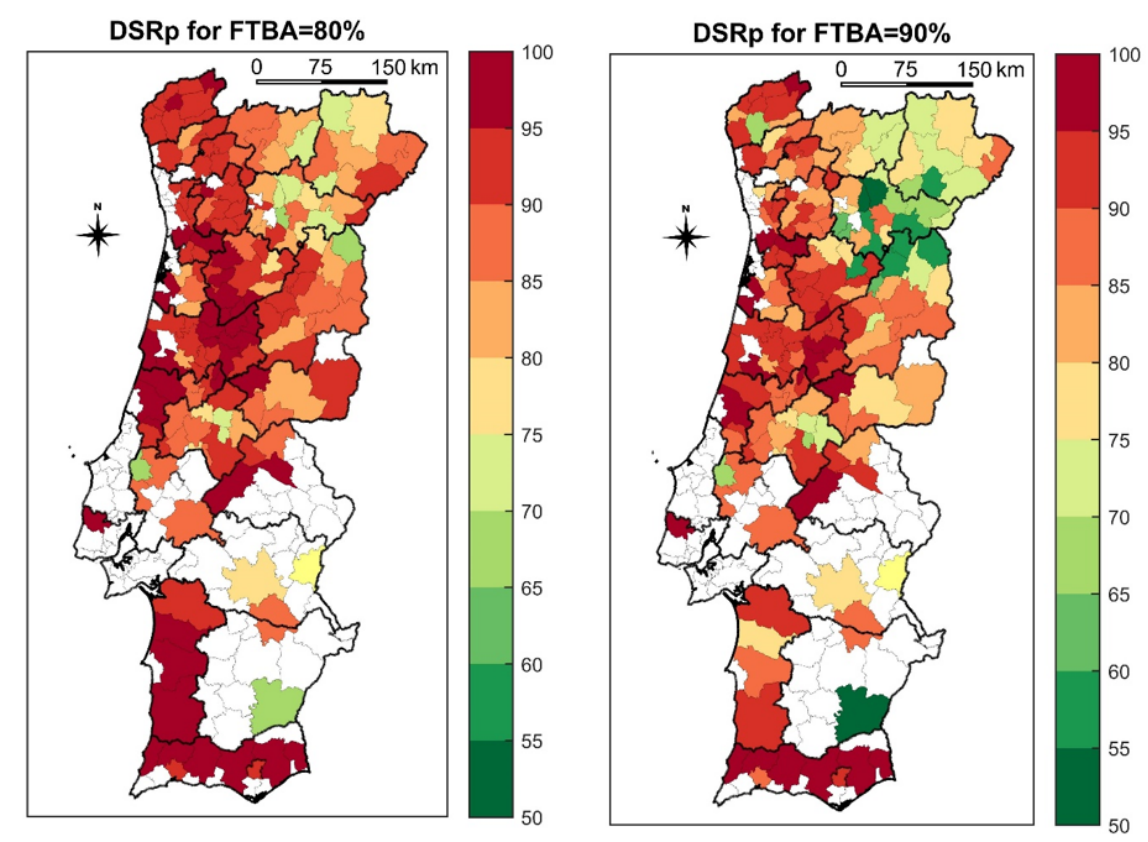

Figure 4. DSR percentile (DSRp) for $80 \%$ (left panel) and $90 \%$ (right panel) of the fraction of total burnt area (FTBA) in each municipality. 
https://doi.org/10.5194/nhess-2021-173

Preprint. Discussion started: 30 June 2021

(c) Author(s) 2021. CC BY 4.0 License.

(c) (i)
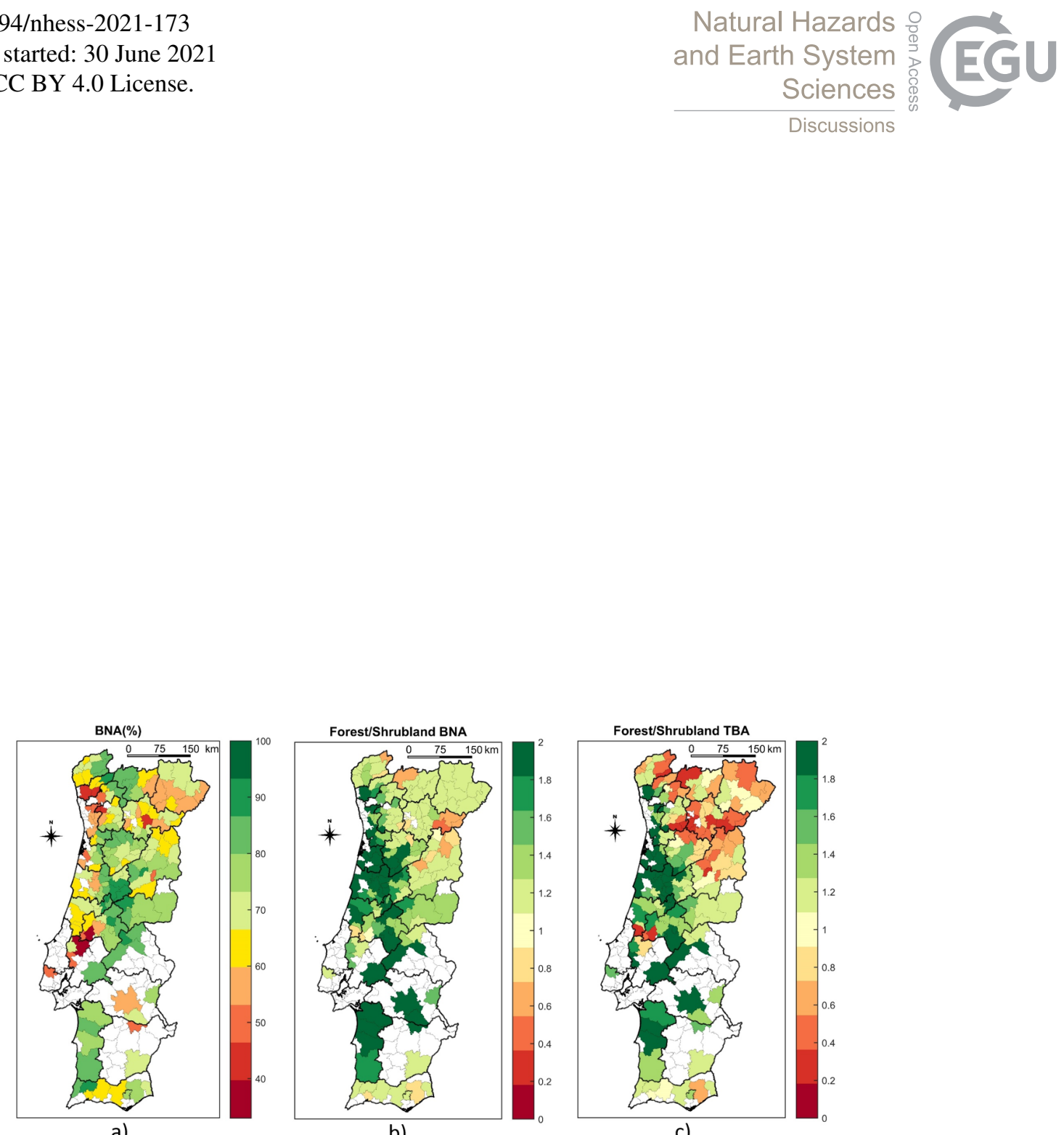

b)

c)

Figure 5. a) Burnable area (BNA), in percentage; b) Forest/Shrubland BNA and c) Forest/Shrubland total burnt area (TBA); all in the 2001 -2019 period, for the selected municipalities. 
https://doi.org/10.5194/nhess-2021-173

Preprint. Discussion started: 30 June 2021

(c) Author(s) 2021. CC BY 4.0 License.

(c) (i)
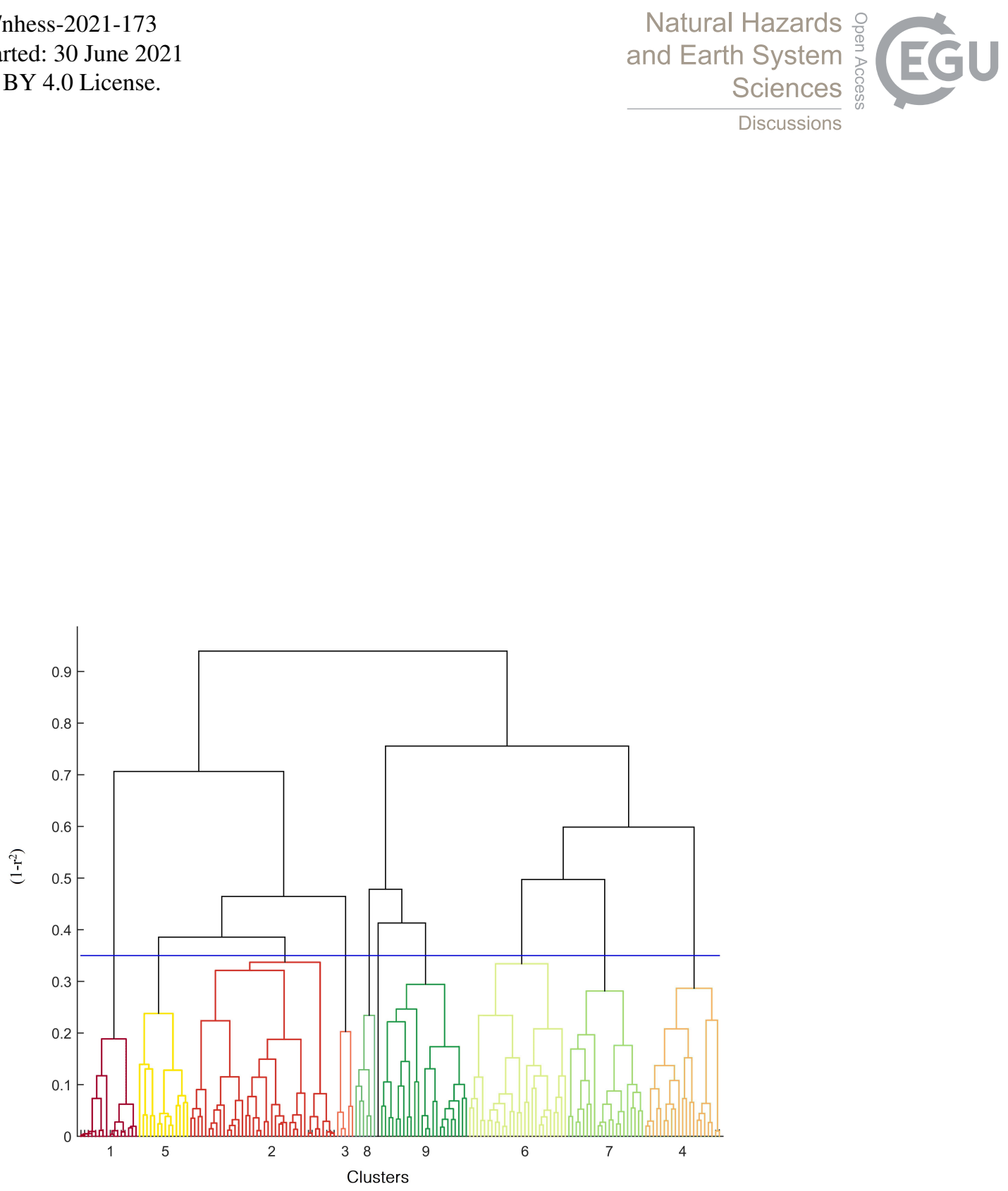

Figure 6. Dendrogram results: cluster colours are the same as in Figure 7, for better identification. $X$ axis numbers are the cluster numbers. $\mathrm{Y}$ axis is (1-r2), where $r$ is the correlation coefficient between FTBA and DSRp. Blue line is the clustering threshold, at 0.35. Each vertical line is a municipality. 
https://doi.org/10.5194/nhess-2021-173

Preprint. Discussion started: 30 June 2021

(c) Author(s) 2021. CC BY 4.0 License.

(c) (i)

\section{Natural Hazards and Earth System Sciences \\ Discussions}

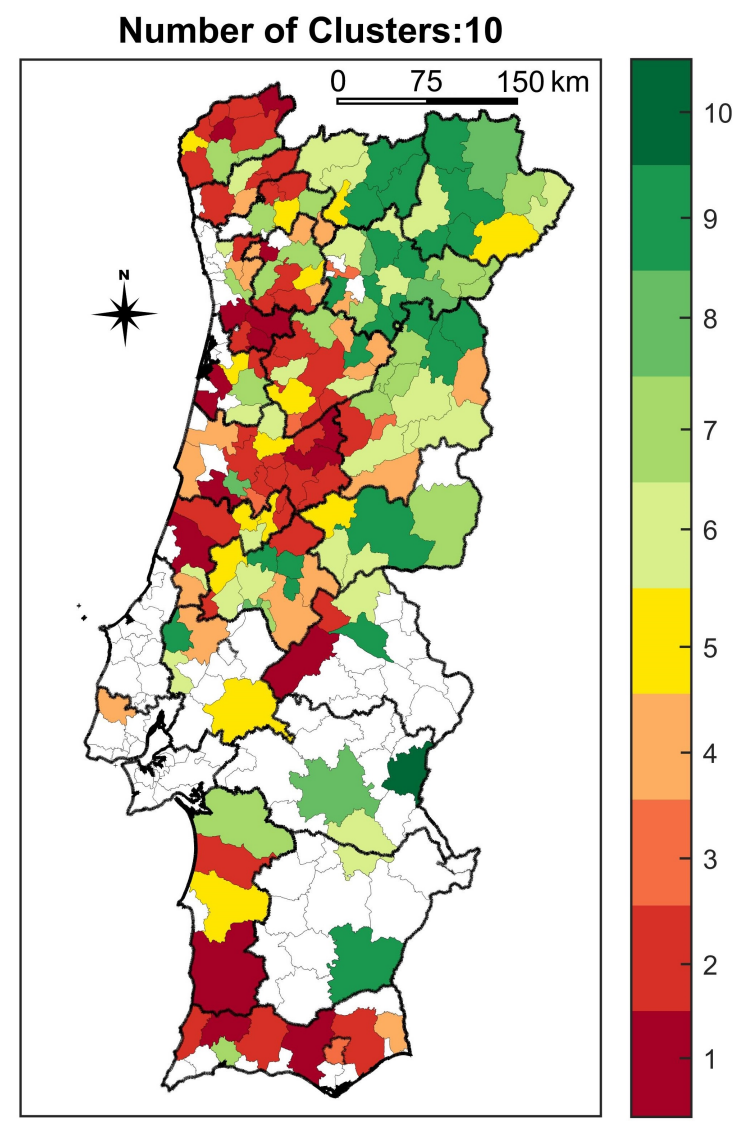

Figure 7. Clusters spatial distribution. Cluster colours are the same as in Figure 6. Municipalities without colour were excluded from the cluster analysis, justifying only $5.2 \%$ of TBA. 
https://doi.org/10.5194/nhess-2021-173

Preprint. Discussion started: 30 June 2021

(c) Author(s) 2021. CC BY 4.0 License.

(c) (i)
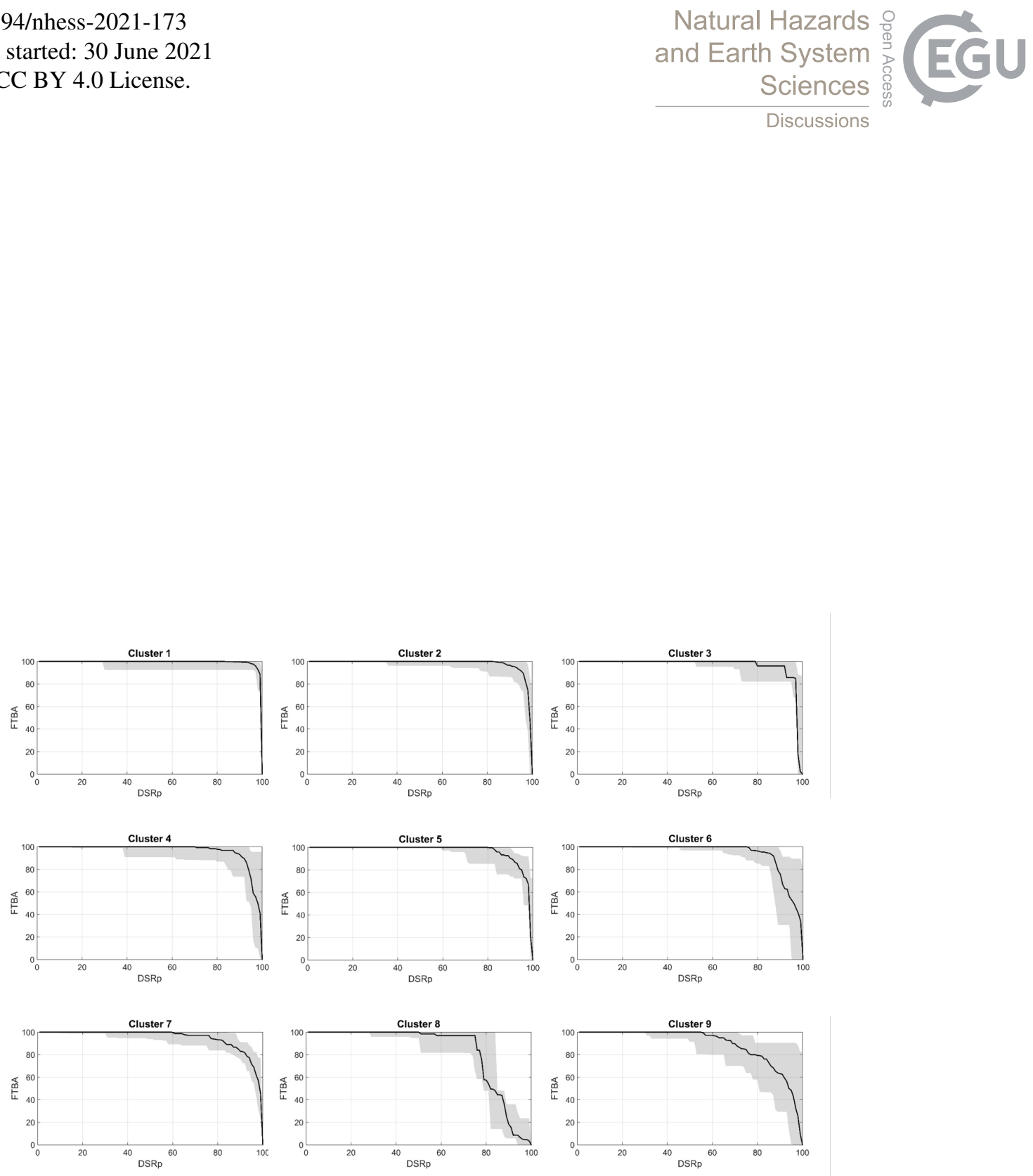

Figure 8. Fraction of total burnt area (FTBA) vs DSR percentile (DSRp), for the municipalities of each of the 9 clusters. Black line is the median of all curves in each cluster. Shaded area is defined by the maximum and minimum curves in each cluster. 

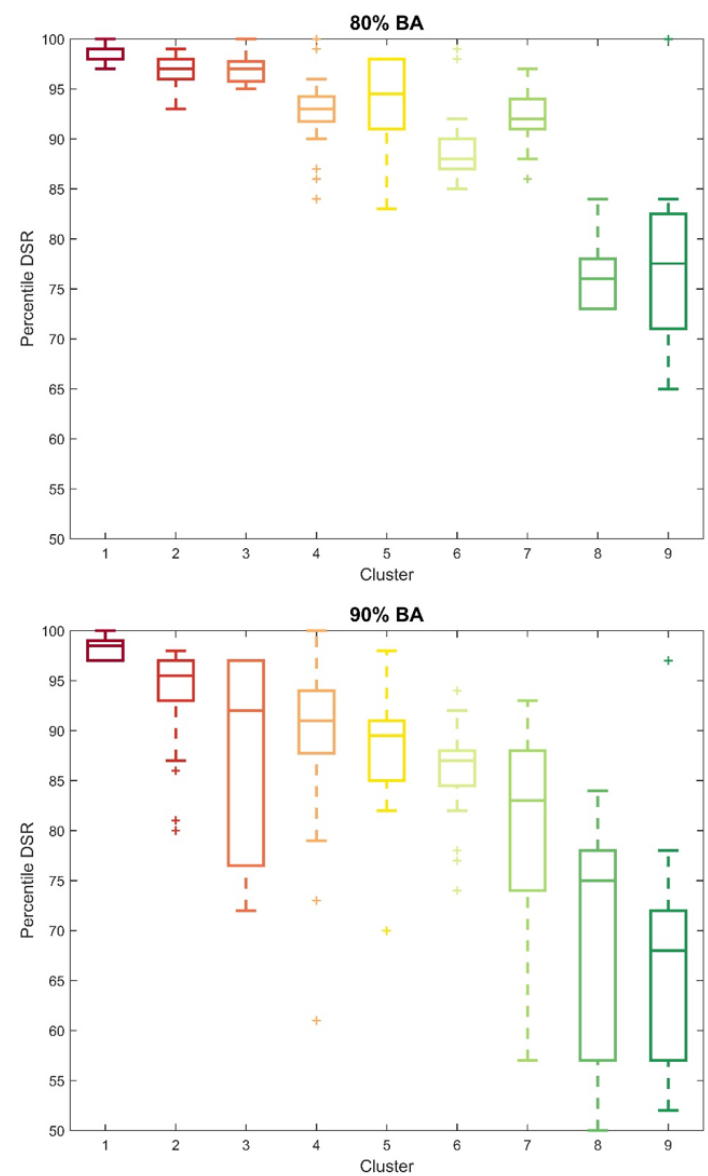

Figure 9. Boxplots for the DSRp when the municipality curves reaches $80 \%$ (top) and $90 \%$ (bottom) BA, for the 9 clusters. The central line is the median; the edges of the box are the 25th and 75th percentiles; and plus sign are the outliers. 
https://doi.org/10.5194/nhess-2021-173

Preprint. Discussion started: 30 June 2021

(c) Author(s) 2021. CC BY 4.0 License.

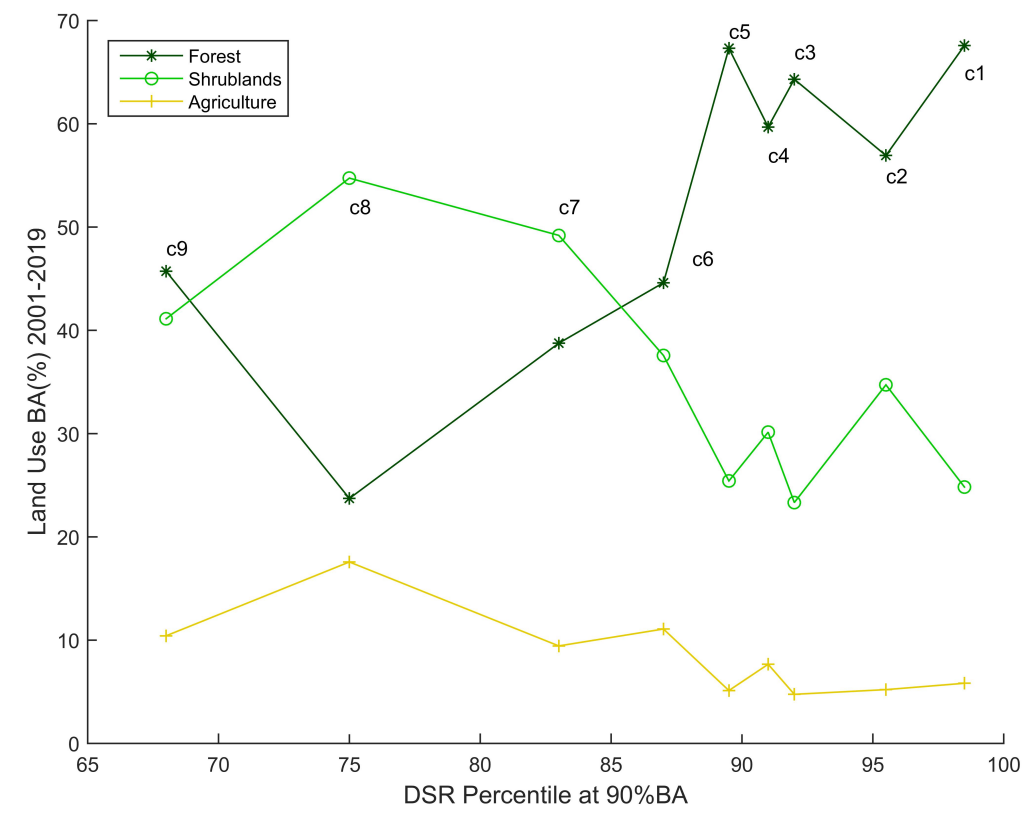

BA in Land Use type

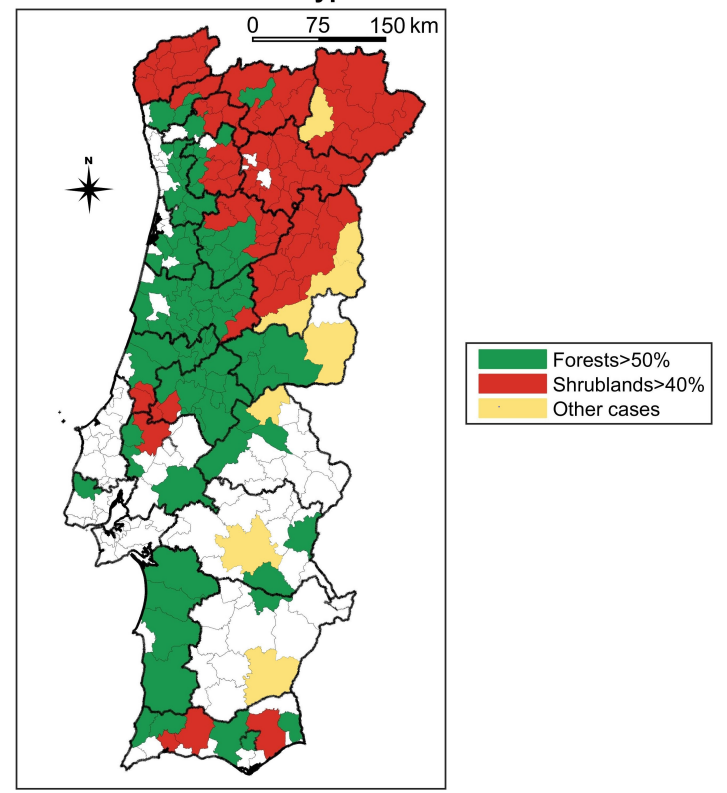

Figure 10. Top: Burnt area in three land use types: forest, shrublands and agriculture; represented for each cluster, identified by the respective DSRp and also by letter c. Bottom: Municipalities with Burnt Area in Forest $>50 \%$, Shrublands $>40 \%$ or other cases Municipalities without colour were excluded from the cluster analysis. 
https://doi.org/10.5194/nhess-2021-173

Preprint. Discussion started: 30 June 2021

(c) Author(s) 2021. CC BY 4.0 License.

(c) (i)

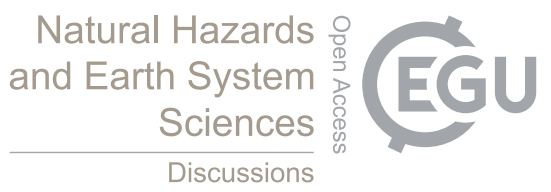

Table 1. Contingency tables and accuracy metrics to assess the role of vegetation BA assessed with DSRp90BA thresholds, for the municipalities used in cluster analysis. The contingency tables computed the number of municipalities (NM) for the following criteria: CLUST 1-5 (CLUST 7-9) and BAF>50\% (BAS+BAA>50\%). Overall Accuracy (OA), User's Accuracy (UA) and Producer's Accuracy (PA) were the calculated accuracy metrics, together with the statistical tests Chi-squared $(\chi 2)$ test (with p-value), Phi coefficient $(\Phi)$, Contingency coefficient (C) and the Cohen's Kappa coefficient $(\kappa)$.

\begin{tabular}{|c|c|c|}
\hline NM & BAF $>50 \%$ & BAS+BAA $>50 \%$ \\
\hline CLUSTERS 1-5 & 65 & 27 \\
\hline CLUSTERS 7-9 & 14 & 33 \\
\hline OA & \multicolumn{2}{|c|}{$71 \%$} \\
\hline UA & $71 \%$ & $70 \%$ \\
\hline PA & $82 \%$ & $55 \%$ \\
\hline$\chi 2$ & \multicolumn{2}{|c|}{$21.175(4 \mathrm{E}-6)$} \\
\hline$\Phi$ & \multicolumn{2}{|c|}{0.390} \\
\hline C & \multicolumn{2}{|c|}{0.363} \\
\hline$\kappa$ & \multicolumn{2}{|c|}{0.383} \\
\hline
\end{tabular}


https://doi.org/10.5194/nhess-2021-173

Preprint. Discussion started: 30 June 2021

(c) Author(s) 2021. CC BY 4.0 License.

(c) (i)

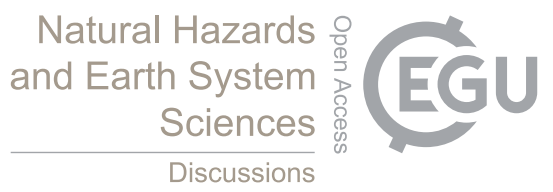

Number of fires 2001-2019

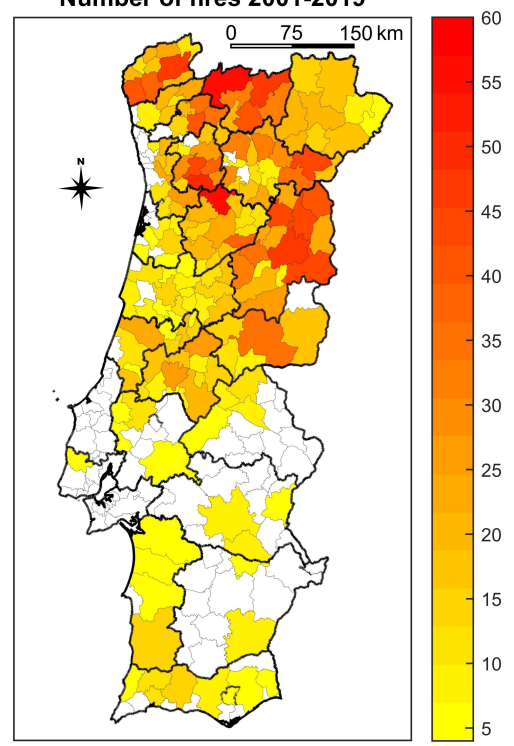

Figure A1. Number of fires larger than 100 ha, all in the 2001 - 2019 period, for the selected municipalities. 